\title{
Wage Inequality, Labor Market Polarization and Skill-Biased Technological Change: An Evolutionary (Agent-Based) Approach
}

\author{
Patrick Mellacher ${ }^{1}$ (D) Timon Scheuer $^{2}$
}

Accepted: 16 July 2020 / Published online: 6 August 2020

(c) The Author(s) 2020

\begin{abstract}
We replicate the core model of the well-tested Keynes + Schumpeter agent-based model family, which features an endogenous innovation process in the evolutionary tradition based on invention and imitation. We introduce heterogeneous labor in the form of three different types of workers, representing different skill levels. In addition to a number of other stylized facts, which are reproduced by any Keynes + Schumpeter model, our version also generates wage inequality and labor market polarization due to skill-biased technological change. We introduce various labor market institutions and policies to our artificial economy in order to test, whether and how they affect inequality and polarization. Those policies, which alter relative wages induce an evolution of the technological development towards a lower demand for the relatively expensive type of worker. Policies and institutions that only aim at increasing the relative wages of low- and medium skilled workers therefore prove to be unable to combat inequality in the long run on their own. In order to be effective, those policies must be combined with educative measures that allow the workers to adapt to the changes in labor demand. Our findings have important implications on the design of real-world policies against inequality and polarization, since they shed light on potential unintended consequences of some of these policies.
\end{abstract}

Keywords Innovation · Agent-based model $\cdot$ Schumpeter $\cdot$ Directed technological change $\cdot$ Job polarization $\cdot$ Wage polarization

JEL Classification $\mathrm{B} 52 \cdot \mathrm{C} 63 \cdot \mathrm{J} 2 \cdot \mathrm{J} 31 \cdot \mathrm{O} 31 \cdot \mathrm{O} 33 \cdot \mathrm{O} 4$

Patrick Mellacher

patrick.mellacher@uni-graz.at

1 Graz Schumpeter Centre, University of Graz, Universitätsstraße 15, 8010 Graz, Austria

2 Institute of Accounting and Taxation, University of Graz, Universitätsstraße 15, 8010 Graz, Austria 


\section{Introduction}

Rising wage inequality is a widely discussed phenomenon, especially for the USA where it has been observed since the 1980s (see Autor 2014). A number of possible explanations have been proposed and investigated, including globalization (see Helpman 2017), the worker composition of firms (high-wage workers more often work in high-wage firms), as well as the rise of very large firms (see Song et al. 2018) and the diminished power of trade unions (Card 2001; Pontusson 2013). By the end of the last century, however, the hypothesis that new technologies are skillbiased to the benefit of higher-skilled workers (see Autor et al. 1998) became the "standard explanation" (Acemoglu 2002). Acemoglu (1998, 2002) delivers a theoretical framework for this observation. He assumes that new technologies can be designed in a way that they fit the currently available skills (so-called directed technological change). ${ }^{1}$

In the beginning of the $2000 \mathrm{~s}$, however, this view was challenged. Autor et al. (2003) argue that the effect of computing technologies is twofold: they complement non-routine tasks (which are typically performed by high-skilled, but also lowskilled labor) and substitute routine tasks (typically performed by medium-skilled workers). For example, computers support the work of scientists and (at this point) do not threaten the existence of their jobs, whereas travel agents were hit hard by the ability of customers to book their flights and hotels on the internet. Goos and Manning (2007) introduced the term "job polarization" to describe that mediumskilled workers are most affected by substitution as their jobs are automated and vanish. On the other hand, low-skilled as well as high-skilled jobs (or, as they put it, "lousy and lovely jobs") are on the rise. This result was confirmed repeatedly for the U.S. and Europe (Goldin and Katz 2007; Goos et al. 2009; Autor and Dorn 2013). Autor and Dorn (2013) and Autor (2015) speak, more broadly, of a polarization of the labor market and show that the polarization in employment was accompanied by a polarization of wages. Whether or not this trend will continue remains to be seen. Among others, Brynjolfsson and McAfee (2011), as well as Frey and Osborne (2017) suggest that new technologies become more and more sophisticated by the minute which might lead to a situation in which low- and high-skilled jobs are increasingly threatened as well. Meanwhile, the idea of directed technological change was developed further. Acemoglu and Restrepo (2018) develop a framework in which directed technological change may lead to excessive automation that lead to wages which are relatively too high compared to the rental rate of capital (e.g. due to labor market rigidities). In the most sophisticated version of this model to date, a potential skill-mismatch between low and high-skilled labor is highlighted. To fully

\footnotetext{
${ }^{1}$ Acemoglu was not the first economist to implement the idea of directed (or induced) technological change in a neoclassical framework. His contribution, however, was able to reconcile two facts with neoclassical economics which it seemed to contradict before: the simultaneous increase of supply of highskilled labor and the skill premium since the 1980s (see Brugger and Gehrke 2017, for a literature survey).
} 
reap the benefits of new technologies, but also to decrease inequality, the skill-level of the population has to be increased (see Acemoglu and Restrepo 2018a).

We want to contribute to the understanding of the relationship between wage inequality, polarization and skill-biased technological change by putting forward an approach that combines two aspects of technological change: technical and economic feasibility. Following Schumpeter ([1934] 2012), we distinguish between inventions and innovations. Inventions open up new possibilities to produce a certain (old or new) good. But they will only become economically relevant if somebody (an entrepreneur or established firm) innovates by actually using this possibility and that only occurs if it is profitable to do so. The innovation process therefore crucially depends on prices: how much do the inputs cost and how much can a firm charge for the outputs? In other words, just because a technology becomes invented, i.e. technically feasible, it doesn't mean that it will lead to an innovation, as only economically feasible technologies will be used. For example, fast food restaurants increasingly rely on self-service kiosks instead of human cashiers. Those kiosks substitute for (unskilled) labor, as well as land (as kiosks take up much less space). While this technology is available worldwide, it is more likely to be used in countries and areas where (unskilled) labor and land are relatively expensive, as the investment only then pays off. ${ }^{2}$

From this point of view, a potential skill-bias of technological change may arise both in the invention, as well as in the innovation process. It is much easier to invent a machine that replaces human cashiers than a technology that substitutes doctors. But doctors are very expensive, so there is a huge incentive to automate at least some of the tasks they perform. For a start, artificial intelligence is thought to play a big role in radiology in future (Chartrand et al. 2017).

Our approach thus combines both the perspectives of Autor et al. (2003), who emphasize the technical skill-bias of computing technology, as well as Acemoglu $(1998,2002)$ who assumes that the direction of technological change (and thus, a potential skill-bias) is determined (at least partly) by supply and demand.

We also assume that technological change adds up-the invention of self-service kiosks, for instance, depended on continuous improvements that made computers ever smaller and cheaper-and thus is path-dependent. If this is the case, the trajectory of technological change may not easily be reversed, even if the direction of future innovations changes.

To model our approach, we replicated the core model of the Keynes + Schumpeter agent based model family (Dosi et al. 2006, 2008, 2010, 2013, 2015, 2017) which seems to be perfectly suited as it features endogenous growth that is based on an invention, innovation and imitation process at the firm level. We tried to follow the reference model very closely and avoid major deviations. We then modified it by introducing heterogeneous labor in the form of three types of workers which assume different roles in the production process and are differently affected by technological change.

\footnotetext{
${ }^{2}$ The use of this technology obviously also depends on customer acceptance.
} 
One may argue that technological change could be implemented using a much simpler model. But we assume that the technological development, the goods and the labor markets are interdependent and therefore require a general analysis. We chose agent based modeling, as it allows us to study (a) technological change and inequality, which are inherently heterogeneous processes and (b) how technological change and the labor markets are shaped by equilibrating, but also by disequilibrating forces. Instead of creating a new model from scratch, we chose to follow an established one and only change it modestly to make our point. As we concede in Sect. 5.3, we are not fully satisfied with every single mechanism that we implemented. In the future, we plan to further improve on the model, but do so on a stepby-step basis to be able to grasp the effects of every small change.

On the one hand, our model reproduces important insights from the previously cited well-known general equilibrium models concerned with the impact of technological change on heterogeneous workers, as well as from agent based models (see Sect. 5.1). On the other hand, it produces some distinct results which seem to be a promising starting point for further research (see Sects. 5.2 and 5.3).

By the time we set up our model, a number of general agent-based models involving technological change and heterogeneous skills were published that we are aware of (see Dawid and Delli Gatti 2018, for a literature survey of recent macroeconomic ABMs). Dosi et al. (2019a) introduce skill level as a continuous variable (acquired by on-the-job-training) into the original $\mathrm{K}+\mathrm{S}$ model and thus also includes endogenous technological change, which however is not skill-biased.

The Eurace@Unibi model (see e.g. Dawid et al. 2018) and Eurace Simulator (see e.g. Ponta et al. 2018) offer two-fold heterogeneity: Workers have a certain general skill-level (which may be upgraded by policies as in Dawid et al. 2009) and specific skills, acquired by on-the-job training. The former model has been used to study the relationship between technological change and inequality under skill-heterogeneity as the authors assume complementarity between capital productivity and skill level. The latest technologies can only be fully productive if they are operated by workers who have acquired a certain skill level (see Dawid et al. 2018). Technological change in the Eurace @Unibi and the Eurace Simulator models is therefore in a way skill-biased towards higher-skilled workers. In contrast to our model, however, technological change is exogenously given and thus not influenced by the conditions at the labor market (i.e. it is not directed). The skill-bias also monotonically favors higher-skilled workers and thus does not account for the aforementioned observation by Goos and Manning (2007), Autor et al. (2003) and others that technological change in fact affects medium-skilled workers most.

A model by Silva et al. (2012) features heterogeneous labor in the form of routine and non-routine workers. Although this distinction seems to be inspired by empirical work a la Autor et al. (2003), their model also produces wage inequality in the absence of routine-biased technological change. Georges (2017) describes a model emphasizing the effects of product innovation in the consumption good sector on inequality between two types of workers. Naturally, both models do not feature polarization tendencies, since they confine themselves to two types of workers.

Finally, Caiani et al. (2019) feature a segmented labor market like ours, as well as endogenous technological growth. Caiani et al. (2018) expand their 
analysis and specifically analyze whether wage inequality fosters economic growth or not. Technological growth in their model is not skill-biased and higher wages for the lower classes of society actually encourages growth as aggregate demand is strengthened. Crucially, they assume that technological change does not affect the capital-labor ratio, which is assumed to be constant, but only capital productivity. The same is true for the Eurace@Unibi model. As further elaborated below, we make the exact opposite assumption, which leads us to different results.

Agent-based models are also fruitfully employed to study the interrelationship between innovation, growth and inequality in the absence of heterogeneous labor. Vallejos et al. (2018) present an agent-based model, which is able to replicate the empirical tendencies towards wealth inequality in the United States. Palagi et al. (2017) analyze the effects of income inequality on macroeconomic performance. Neves et al. (2019) offer an agent-based interpretation of the "The Race between Man and Machine" emphasized by Acemoglu and Restrepo (2018) and Acemoglu and Restrepo (2018b) and, like the latter models, also uses a task-based framework and analyzes the counteractive effects of the discovery and automation of tasks.

Our contribution is threefold: (1) We show that the well-known Keynes + Schumpter computational model can be modified with modest adaptions to produce wage inequality and job, as well as wage polarization-tendencies that are observed in the real world. (2) We model explicitly labor market policies that could be used by governments and trade unions trying to decrease wage inequality. We show that trying to set artificially high wages for low-skilled workers has the unintended consequence that technological change becomes skill-biased, which results in a higher unemployment rate for low-skilled workers. As discussed above in the context of self-service kiosks, there is reason to believe that such an unintended consequence could also be triggered in the real world. (3) We offer a Schumpeterian view of skill-biased technological change that distinguishes between technical and economic skill-biases. The economic skill-bias in our model represents an alternative to the mainstream approach to directed technological change by Acemoglu (1998) and his subsequent work and has immediate policy implications. In our model, highly skilled workers benefit from the fact that their supply is limited, which would be a disadvantage in Acemoglu's models. In our model, a sustainable decrease of wage inequality is only possible if many low- and medium-skilled workers are upskilled. But if there is a conflict of interest, upskilling policies are much less likely to be implemented.

The rest of the paper is organized in the following way: The next section gives an overview of the model and describes the sequence of events. The third section discusses the behavior of the agents in the model in detail. We then introduce different labor market institutions and policies that we are experimenting with. In the fifth section, we show how we validated our model and present the results of our labor market experiments. The final section concludes. The initial parameters of the model are displayed in "Appendix". 


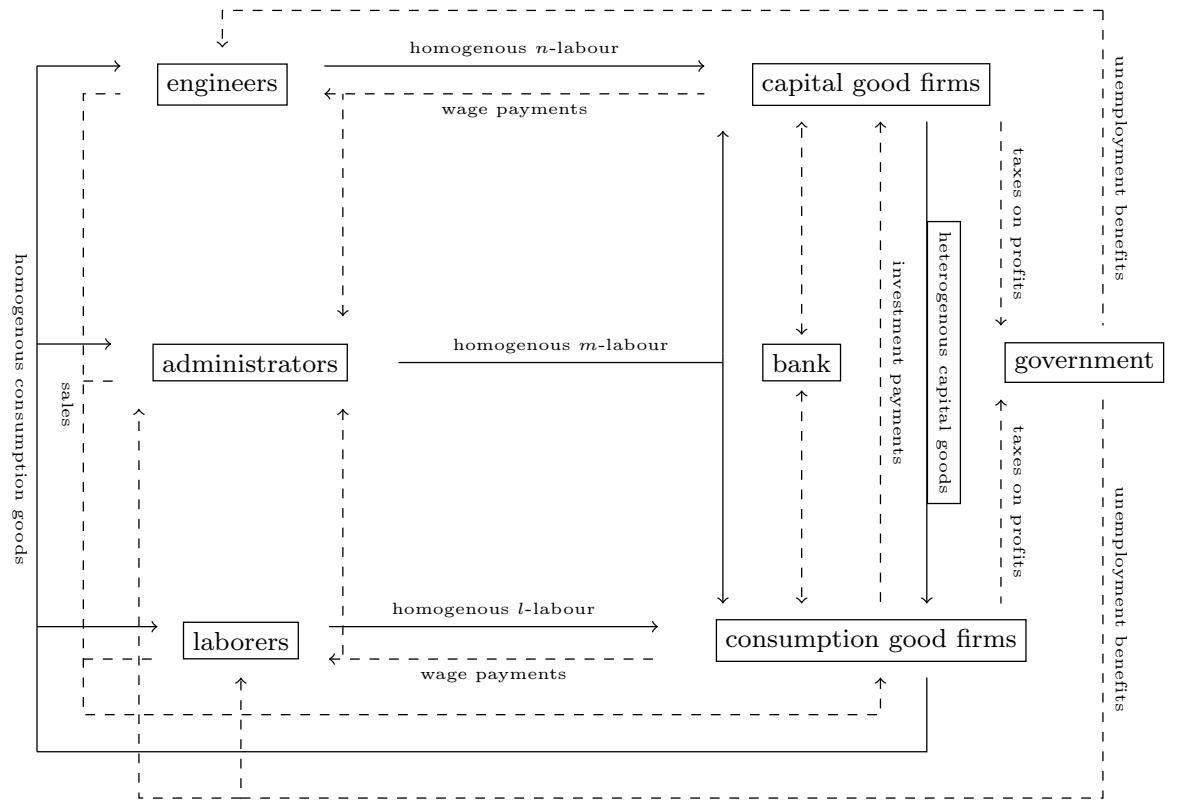

Fig. 1 Flow diagram of the model—dashed lines represent money flows

\section{Overview of the Model}

Dosi et al. $(2017,167)$ describe the Keynes + Schumpeter model as a "general disequilibrium agent-based model, populated by heterogeneous firms and workers, who behave according to boundedly rational behavioural rules". We tried to stick very closely to the original model with regard to the behavior of the agents and change it only if we deemed it to be absolutely necessary. We implemented our version of the Keynes + Schumpeter model with the programming language NetLogo (Wilensky 1999) using the behavioral equations as we found them in the original papers by Dosi et al. to replicate the original agent behavior. Our version of the model is as shown in Fig. 1, populated by:

- Three different types of workers who represent different skill levels. Engineers (high-skilled workers) are employed by capital good firms, laborers (low-skilled workers) work at consumption good firms and administrators (medium-skilled workers) are needed in both types of firms. Employed workers receive a wage rate that depends on their occupation and the unemployed receive a fraction of their last wage as benefits from the government. Workers then use their funds to buy as many consumption goods as possible and save the rest of the money for the next period (if there is excess demand).

- Two different types of firms. Consumption good firms produce homogeneous consumption goods using labor from laborers and administrators, as well as (heterogeneous) capital goods. Capital good firms use labor from engineers and administrators to invent new prototypes of machines, which are offered to con- 
sumption good firms and produced on demand. Consumption good firms invest in new capital goods (machines) by buying them from capital good firms. Firms operate with a price markup on variable costs, both because they need to fund their investments and because they operate under imperfect competition.

- Capital goods which are characterized by the amount of engineer labor that is used in their production, the laborers labor necessary in their operation and the administrator labor used in both processes.

- A bank which provides credit to both types of firms, if they are considered to be solvent and charges an interest rate on debts.

- A government which charges a flat-rate tax on profits of both types of firms and pays benefits to unemployed workers.

\subsection{Sequence of Events}

The following sequence of events takes place in each period: ${ }^{3}$

1. Price setting (1) Consumption good firms set their price markup (Eq. 3). Capital good firms set their prices according to a fixed markup on variable costs (Eq. 1).

2. Advertisement Capital good firms advertise their most attractive prototype (Eq. 2).

3. Demand for capital goods Consumption good firms check how many new machines they expect to need in the upcoming period and order the most attractive type they know of (Eqs. 8-11). ${ }^{4}$

4. Production planning Consumption good firms plan their production according to their expectations about future demand (Eqs. 4-7). Capital good firms plan according to the orders they received.

5. Labor demand All firms calculate their labor demand and announce vacancies and dismissals (Eqs. 12-16).

6. Labor market interaction (1) All firms fire excess workers.

7. Labor market interaction (2) All workers adapt their reservation wages (Eqs. 35 or 36). Unemployed workers apply to firms which offer vacancies matching their skills and wage expectations.

8. Labor market interaction (3) Firms hire out of their queues of applicants. The firms with the highest wage offers are able act first.

9. Production All firms produce according to their plans (Eqs. 17 and 18).

10. Research and Development Capital good firms try to invent new prototypes and imitate their competitors (Eqs. 19-21).

11. Wage payment All firms pay wages to employees. Unemployed workers receive benefits (Eq. 29).

12. Price setting (2) Consumption good firms set their prices (Eq. 3).

\footnotetext{
3 We refer to the respective equations in parentheses.

4 The "attractiveness" of a certain type of machine depends on its costs in production and operation, see Sect. 3.1.1 for more details.
} 
13. Consumption goods market Workers try to buy as many consumption goods as possible and save the rest of their funds for the next period. Sales are allocated to consumption good firms (Eqs. 22-25).

14. Capital goods market New machines are delivered to and paid for by the consumption good firms.

15. Depreciation Old capital stock depreciates and machines that reach the end of their life span are discarded.

16. Profits All firms calculate their profits and pay taxes on them (Eq. 26, 27).

17. Upskilling Unemployed workers may upskill. ${ }^{5}$

18. Wages Workers decide whether they want to bargain. All firms adapt their wage offers and bargaining workers decide whether to accept the offer or quit (Eqs. 31 and 32 or 33 and 34 ).

19. Insolvencies Insolvent firms are bailed out. ${ }^{6}$

\section{Agent Behaviors}

This section describes the behavior of firms, workers, the bank and the government. Within each type of agent, we aim to describe the model in the exact same order as it appears in the code of our program (and the sequence of events described in Sect. 2.1). We tried to follow the behavioral equations of the $K+S$ model family as closely as possible and only adapted them when we deemed it to be necessary in order to deal with problems that we encountered during the verification phase. An exception was made for the mechanism regarding wage increases for employees, where we introduced a bargaining mechanism in the form of an ultimatum game.

To keep track of all the variables used, we use the following indices: 1 stands for laborer, $\mathrm{m}$ for administrator, $\mathrm{n}$ for engineer, $\mathrm{j}$ for a consumption good firm, $\mathrm{J}$ for all consumption good firms, $\mathrm{i}$ for a capital good firm, I for all capital good firms, $\mathrm{t}$ for period, $\mathrm{k}$ for a capital good/prototype, h for workers of more than one type (e.g. both laborers and administrators, $\mathrm{h}$ is always defined in the equation), $\mathrm{g}$ for both types of firms.

\subsection{Firms}

\subsubsection{Pricing and Advertisement}

Capital good firms dispose of a growing variety of prototypes for machines gained from Research \& Development, from which they can offer a single prototype to their customers, which are consumption good firms. In the beginning of each period, they want to determine, which prototype they want to offer. In order to do that, capital good

\footnotetext{
${ }^{5}$ Not possible in the baseline scenario.

${ }^{6}$ We adopted the assumption of Dosi et al. (2010) that the number of firms is fixed. But to secure stockflow consistency we wanted to avoid the creation of new firms with new capital stock or knowledge coming out of nowhere like dei ex machina.
} 
firms recalculate the price $p^{k}$ and subsequently the cost factor $\rho^{k}$ of each prototype they are able to produce. The calculations depend on the wage rates of laborers $w^{l}$, administrators $w^{m}$ and engineers $w^{n}$ in period t as well as on the labor intensities of production. A laborer intensity $\lambda_{k}^{l}$ of two means that two laborers are needed to operate the machine $\mathrm{k}$. An engineer intensity $\lambda_{k}^{n}$ of two means that two engineers are needed to produce the machine $\mathrm{k}$. An administrator intensity $\lambda_{k}^{m}$ of two means that two administrators are needed for every laborer or engineer needed in the production processes of machine $\mathrm{k}$. Capital good firms set their prices $p_{i, t}^{k}$ by adding a fixed markup $\mu_{I}$ on unit production costs, which are given by the intensities as described above and the wage rate that firm $\mathrm{i}$ offers to new engineers $w_{i, t}^{n}$ and administrators $w_{i, t}^{m}$ in period t.

$$
p_{i, t}^{k}=\left(1+\mu_{I}\right)\left(\left(w_{i, t}^{n}+w_{i, t}^{m} \lambda_{k}^{m}\right) \lambda_{k}^{n}\right)
$$

When consumption good firms decide, which capital good they want to buy, they do not solely compare the prices of machines, but try to approximate the total lifetime costs of each machine based on a cost factor $\rho_{k, t}$, which also takes into account the runtime costs within a fixed payback period $\tau_{J}$. Capital good firms know this, but do not know the exact wage rates of their potential customers and thus calculate the cost factor using average wage rates $\bar{w}_{J, t}^{l}$ and $\bar{w}_{J, t}^{m}$.

$$
\rho_{k, t}=p_{i, t}^{k}+\tau_{J}\left(\bar{w}_{J, t}^{l}+\bar{w}_{J, t}^{m} \lambda_{k}^{m}\right) \lambda_{k}^{l}
$$

Once the capital good firms calculated $\rho_{k, t}$ for all prototypes at their disposal, they select the prototype with the lowest $\rho_{k, t}$ in period $\mathrm{t}$ (which is $\rho_{i^{\star}, t}$ ) and advertise it to all consumption good firms that once ordered machines from the firm (their historical customers) as well as to a random set of new consumption good firms. The number of new firms, to which advertisements are sent, is given by multiplying the number of historical customers with the parameter $l_{1}$. Consumption good firms try to adaptively increase their market share and profits by setting their price markup $\mu_{j, t}$ based on the development of their assigned market share $\tilde{z}_{t}$ (see Eq. 22), which is weighted by the parameter $\bar{\mu}_{J}$. If the market share increased in the last period, markup is raised and vice versa. We introduced a minimum markup, which is given by the interest rate charged on debt $\omega_{4}$ and serves to keep the markup strictly positive. The price $p_{j, t}$ is calculated by adding the markup to variable costs of production. The latter is given by dividing the sum of actual wages $w_{h, t}$ of laborers and administrators employed by the firm by total output of the firm $q_{j, t}$ and can thus only be calculated after the production processes are completed.

$$
\begin{aligned}
& \mu_{j, t}=\max \left(\omega_{4}, \mu_{j, t-1}\left(1+\bar{\mu}_{J} \frac{\tilde{z}_{j, t-1}-\tilde{z}_{j, t-2}}{\tilde{z}_{j, t-2}}\right)\right) \\
& p_{j, t}=\left(1+\mu_{j, t}\right) \frac{\sum_{h^{\star}} w_{h, t}}{q_{j, t}} \mid h^{\star}=\{l, m \text { : employed by } j\}
\end{aligned}
$$




\subsubsection{Expectations and Investment}

After setting their markups, consumption good firms calculate the real demand they expect for their consumption goods in the current period $d_{j, t}^{e}$, which in turn determines their demand for workers and new machines. Their calculation depends on the nominal sales and their development. More specifically, firms are geared to the nominal demand they faced in the last period, which is given by either the sales assigned $z_{j, t}^{d}$ (which is calculated from the assigned market share and the market size, see Eq. 24) or the actual sales $z_{j, t}$ ), whichever is higher. They do not, however, expect their nominal demand to be constant, but to develop in a similar way as it did in the last period. They thus calculate an expected growth rate, which is the growth of nominal sales assigned in the past period multiplied with the parameter $\varepsilon$, which is smaller than 1 . Finally, they divide their expected nominal sales by their price to calculate their expected real demand $d_{j, t}^{e}$.

$$
d_{j, t}^{e}=\left(1+\varepsilon \frac{z_{j, t-1}^{d}-z_{j, t-2}^{d}}{z_{j, t-2}^{d}}\right) \frac{\max \left(z_{j, t-1}^{d}, z_{j, t-1}\right)}{p_{j, t}}
$$

Expected demand then influences how much output a firm desires $q_{j, t}^{d}$. But firms add a certain proportion of extra inventories $l_{3}$ in case they are confronted with an unusually high demand and subtract current inventories $x_{j, t}$ left over from the past period, which are given by subtracting last period's real demand from last period's supply $s_{j, t-1}$.

$$
\begin{gathered}
x_{j, t}=s_{j, t-1}-\frac{z_{j, t-1}}{p_{j, t-1}} \\
q_{j, t}^{d}=\max \left(\left(1+l_{3}\right) d_{j, t}^{e}-x_{j, t}, 0\right)
\end{gathered}
$$

Machines have a constant production capacity $\varsigma$ that - together with the total number of machines available to the consumption good firm $k_{j, t}$-determines the number of machines the firm wants to operate in the current period $k_{j, t}^{d}$. This calculation is subsequently used to determine labor demand (see Eqs. 12, 13).

$$
k_{j, t}^{d}=\min \left(k_{j, t}, \frac{q_{j, t}^{d}}{\varsigma}\right)
$$

The expectations for the current period $q_{j, t}^{d}$ are also used to determine how many machines $k_{j, t}^{d^{2}}$ a firm desires to have in the next period. The investment decision $k_{j, i, t}^{i n v}$ then depends on the difference between the desired $k_{j, t}^{d^{2}}$ and actual capital stock $k_{j, t}$ as well as on discarded machines $k_{j, t}^{e x}$ and desired substitutions $k_{j, t}^{s u b}$. The set of the machines currently owned by a firm $\mathrm{j}$ is denoted with $K_{j, t}$. Machines have to be discarded (become part of the set $K_{j}^{e x}$ ) when their age $\phi_{k, t}$ reaches its maximum $\phi^{\text {max }}$. Machines are listed for substitution (they are part of $K_{j}^{s u b}$ ) if they are considered to be technologically obsolescent, which is decided upon comparison of the machine 
with the current prototype offered by the chosen supplier $i^{\star}$. If the unit costs of the new machines are lower and the investment (i.e. the price of the new machine $p_{i^{\star}, t}$ ) pays off within a fixed payback period $\tau_{J}$, the firm wants to replace the old machines. Finally, the firm sends their orders $k_{j, i^{\star}, t}^{i n v}$ to the firm $i^{\star}$, which is the firm offering the prototype with lowest cost factor $\rho_{k, t}$.

$$
\begin{gathered}
K_{j, t}^{e x}=\forall k \in K_{j, t}: \phi_{k, t}=\phi^{\max } \\
K_{j, t}^{s u b}=\forall k \in K_{j, t}: \frac{p_{i^{\star}, t}}{\left(w_{j, t}^{l}+w_{j, t}^{m} \lambda_{k, t}^{m}\right) \lambda_{k, t}^{l}-\left(w_{j, t}^{l}+w_{j, t}^{m} \lambda_{i^{\star}, t}^{m}\right) \lambda_{i^{\star}, t}^{l}} \leq \tau_{J} \\
\wedge\left(w_{j, t}^{l}+w_{j, t}^{m} \lambda_{k, t}^{m}\right) \lambda_{k, t}^{l}>\left(w_{j, t}^{l}+w_{j, t}^{m} \lambda_{i^{\star}, t}^{m}\right) \lambda_{i^{\star}, t}^{l} \\
k_{j, t}^{d^{2}}=\frac{q_{j, t}^{d}}{\varsigma} \\
k_{j, i^{\star}, t}^{i n v}=\max \left(k_{j, t}^{d^{2}}-k_{j, t}+k_{j, t}^{e x}+k_{j, t}^{s u b}, 0\right)
\end{gathered}
$$

\subsubsection{Labor Market Interaction}

Once both consumption and capital good firms know their desired output-consumption good firms plan as described in the last subsection and capital good firms want to fill all orders - they can calculate their desired labor demand. Consumption good firms calculate their demand for laborers $l_{j, t}^{d}$ and administrators $m_{j, t}^{d}$ based on the capital stock they want to use in the current period $k_{j, t}^{d}$ and its associated labor intensities, where $\bar{\lambda}_{j, t}^{l}$ and $\bar{\lambda}_{j, t}^{m}$ denote the average labor laborer and administrator intensity of the capital stock they want to use in this period. If firms do not need their whole capital stock to produce the desired quantity of consumption goods, they always use the least labor-intensive (i.e. the most efficient) machines at their disposal.

$$
\begin{aligned}
& l_{j, t}^{d}=k_{j, t}^{d} * \bar{\lambda}_{j, t}^{l} \\
& m_{j, t}^{d}=l_{j, t}^{d} * \bar{\lambda}_{j, t}^{m}
\end{aligned}
$$

The labor demand of capital good firms for engineers $n_{i, t}^{d}$ depends on the total machine orders $q_{i, t}^{d}$ they receive from the consumption good firms and the engineer intensity $\lambda_{i, t}^{n}$. Additionally, they try to hire as many engineers for $\mathrm{R} \& \mathrm{D} n_{i, t}^{R D}$ as they can afford paying their wage rate $w_{i, t}^{n}$ with a fraction $l_{2}$ of past sales $z_{t-1}$. Finally, the capital good firm needs $\lambda_{i, t}^{m}$ (the administrator intensity) administrators $m_{i, t}^{d}$ per engineer to administrate its workforce. 


$$
\begin{gathered}
n_{i, t}^{R D}=\frac{l_{2} * z_{t-1}}{w_{i, t}^{n}} \\
n_{i, t}^{d}=q_{i, t}^{d} * \lambda_{i, t}^{n}+n_{i, t}^{R D} \\
m_{i, t}^{d}=n_{i, t}^{d} * \lambda_{i, t}^{m}
\end{gathered}
$$

If the difference between labor demand and the current labor force is positive, it is announced as the number of vacancies. We assume that there are no labor market rigidities that prevent redundancies, so any negative difference leads to a corresponding number of dismissals. All dismissals are executed first and workers who were fired can directly apply for a new job.

\subsubsection{Production}

Once all labor market interactions took place, the firms can start to produce. Supply $s_{j, t}$ of consumption good firms is given by their inventories left over from last period $x_{j, t}$ and their production during this period $q_{j, t}$. The produced quantity is given by a Leontief production function, where a fixed proportion of machines $k_{j, t}$, laborers $l_{j, t}$ and administrators $m_{j, t}$ are needed to produce consumption goods. The exact number of laborers and administrators needed per machine (i.e. capital good) is given by the average laborer $\bar{\lambda}_{j, t}^{l}$ and administrator intensity $\bar{\lambda}_{j, t}^{m}$ of the machines that the consumption good firm wants to employ (as described in the subsection before).

$$
s_{j, t}=x_{j, t}+q_{j, t}, q_{j, t}=\varsigma \min \left(k_{j, t}, \frac{l_{j, t}}{\bar{\lambda}_{j, t}^{l}}, \frac{m_{j, t}}{\bar{\lambda}_{j, t}^{m} \bar{\lambda}_{j, t}^{l}}\right)
$$

Capital good firms, on the other hand, produce on-demand and supply $s_{i, t}$ is thus equal to the output in the current period $q_{i, t}$. They need a fixed proportion of engineers and administrators to produce their output given by the administrator $\lambda_{i, t}^{m}$ and engineer intensity $\lambda_{i, t}^{n}$ of the machine they produce in the current period. Capital good firms can only use those engineers and administrators who do not engage in Research \& Development (as described in the next subsection). $n_{i, t}^{R D}$ and $m_{i, t}^{R D}$ denote the number of engineers and administrators, who are assigned to R\&D and $n_{i, t}^{\text {Prod }}$ and $m_{i, t}^{\text {Prod }}$ the number of engineers and administrators who are assigned to producing new machines. The numbers of employees are given by $n_{i, t}$ (engineers) and $m_{i, t}$ (administrators).

$$
\begin{array}{r}
s_{i, t}=q_{i, t}=\min \left(\frac{m_{i, t}^{\text {Prod }}}{\lambda_{i, t}^{m}}, \frac{n_{i, t}^{\text {Prod }}}{\lambda_{i, t}^{n}}\right), n^{\text {Prod }}=\max \left\{0, n_{i, t}-n_{i, t}^{R D}\right\} \\
, m^{\text {Prod }}=\max \left\{0, m_{i, t}-m_{i, t}^{R D}\right\}
\end{array}
$$




\subsubsection{Research and Development}

We can find the Schumpeterian triad of invention, innovation and diffusion at the heart of the model. Capital good firms use a fixed percentage of past sales to employ engineers $n_{i, t}^{R D}$ (as described in Eq. 14) who invent new prototypes and imitate the competitors in every period. Successful inventions, as well as imitations, open up new technical possibilities to produce a machine (i.e. create a new prototype). The number of administrators needed to administrate the engineers assigned to $\mathrm{R} \& \mathrm{D}$ is denoted with $m_{i, t}^{R D}$ and given by $n_{i, t}^{R D}$ and the administrator intensity $\lambda_{i, t^{\circ}}^{m}$

They split their staff into engineers who are assigned to invention $n_{i, t}^{I N}$ and those who imitate $n_{i, t}^{I M}$, where the parameter $v$ denotes the share of R\&D staff allocated to invention. The firm that is technologically most advanced does not want to waste resources on imitation and thus only invents. If a firm was not able to fill all of its vacancies, priority is given to R\&D activities instead of production in order to stay competitive.

$$
\begin{aligned}
& n_{i, t}^{I N}= \begin{cases}v \min \left\{n_{i, t}^{R D}, n_{i, t}\right\} & \text { for followers } \\
\min \left\{n_{i, t}^{R D}, n_{i, t}\right\} & \text { for leaders }\end{cases} \\
& n_{i, t}^{I M}= \begin{cases}(1-v) \min \left\{n_{i, t}^{R D}, n_{i, t}\right\} & \text { for followers } \\
0 & \text { for leaders }\end{cases}
\end{aligned}
$$

Whether or not the attempts to invent and imitate are successful, is determined by a Bernoulli experiment. The probability for a successful invention/imitation $\theta_{i, t}^{I N} / \theta_{i, t}^{I M}$ depends on the number of engineers assigned to the corresponding activity $n^{I N} / n^{i t}$

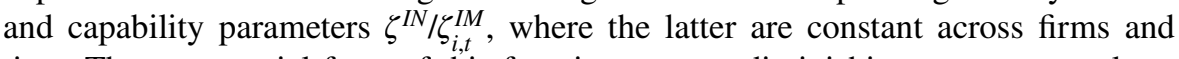
time. The exponential form of this function ensures diminishing returns to scale to $R \& D$ activities.

$$
\begin{aligned}
& \theta_{i, t}^{I N}=1-e^{\left(-\zeta^{I N} n_{i, t}^{I N}\right)} \\
& \theta_{i, t}^{I M}=1-e^{\left(-\zeta^{I M} n_{i, t}^{I M}\right)}
\end{aligned}
$$

Inventions are modeled as new prototypes which are modifications of the prototype that the firm currently sells. New prototypes change the labor intensities of administrators, laborers and/or engineers involved in the production processes. Two separate draws from a Beta distribution, which is defined by its parameters and the interval determined by its supporters $(\alpha, \beta, \gamma, \bar{\gamma})$, determine the changes laborer intensity $\gamma_{i, t}^{l N}$ and engineer intensity $\gamma_{i, t}^{n^{I N}}$. The change of administrator intensity, however, depends on both draws and is therefore amplified, since we assume a technical skillbias against administrators. The labor intensities of a newly invented prototype are denoted with $\lambda_{i, t}^{l^{I N}}$ (laborers needed to operate the machine), $\lambda_{i, t}^{n^{I N}}$ (engineers needed to produce the machine) and $\lambda_{i, t}^{m^{I N}}$ (administrators needed for each engineer or laborer). 
The labor intensities of the currently offered machine (i.e. the base for the modification) are denoted with $\lambda_{i, t}^{l}, \lambda_{i, t}^{n}$ and $\lambda_{i, t^{m}}^{m}$

$$
\begin{aligned}
\lambda_{i, t}^{I^{N}} & =\frac{\lambda_{i, t}^{l}}{\left(1+\gamma_{i, t}^{l^{I N}}\right)} \\
\lambda_{i, t}^{n^{I N}} & =\frac{\lambda_{i, t}^{n}}{\left(1+\gamma_{i, t}^{n^{I N}}\right)} \\
\lambda_{i, t}^{m^{I N}} & =\frac{\lambda_{i, t}^{m}}{\left(1+\gamma_{i, t}^{l^{I N}}\right)\left(1+\gamma_{i, t}^{n^{I N}}\right)}
\end{aligned}
$$

But not any invention/imitation will actually be used (i.e. become an innovation), since modifications to the laborer or engineer intensity do not necessarily have to be labor-saving. For example, a newly invented (or imitated) prototype may need less engineers in its production but more laborers in its operation. Whether or not this prototype will actually be sold, depends on whether the cost factor $\rho^{k}$ of the new machine is the lowest of all machines a capital good firm is able to produce. This, in turn, depends on (a) on the magnitude of the changes and (b) on relative wages. An invention that decreases both laborers and engineer intensities therefore always leads to an innovation. But a new prototype that increases laborers (engineer) intensity and decreases engineer (laborers) intensity, will only be sold if the decrease in runtime costs (price) is perceived to be more important than the increase in price (runtime costs) (see Sect. 3.1.1 again for more details).

This view of technological change, in which firms continuously adapt to their environment (given by the relative wages) dates back to Nelson and Winter (1982) and resembles Darwin's approach to selection, where "each slight variation, if useful, is preserved" Darwin $(1859,61)$ and may therefore be called evolutionary.

We can conclude that technological change in our model is skill-biased against administrators in the invention process (accounting for the empirically observed decline of medium-skilled employment) and possibly against laborers or engineers in the innovation process (if their wages are perceived to be "too high" by the firms).

\subsubsection{Consumption Goods Market Interaction}

Although consumption goods are homogeneous, firms have to decide on their price because the consumption goods market is characterized by imperfect information. The calculation was shown in the Eq. 3 and can be computed once production is completed. Consumers want to avoid firms that charge a relatively high price, but also firms where they encountered empty shelves in the past. Therefore, normalized price ( the price of consumption good firm $\mathrm{j} p_{j, t}$ divided by the average price $\bar{p}_{J, t}$ ) and unsatisfied nominal demand (unsatisfied nominal demand of firm $\mathrm{j}$ of the last period $z_{j, t-1}^{u}$ divided by the average unsatisfied demand $\bar{z}_{t-1}^{u}$ ), which are weighted with parameters $\psi_{3}$ and $\psi_{4}$, determine a value indicating the competitiveness (attractiveness) $\pi_{j, t}$ of the firm. The difference between average $\bar{\pi}_{J, t}$ and individual competitiveness $\pi_{j, t}$ then determines the evolution of the market share that is assigned to the 
firm $\tilde{z}_{j, t}$ according to a replicator dynamic characterized by the parameter $\chi{ }^{7}$ There is a lower bound $\underline{\tilde{z}}_{J}$ to the assigned market share that once reached triggers an insolvency.

$$
\begin{aligned}
& \pi_{j, t}=-\psi_{3} \frac{p_{j, t}}{\bar{p}_{J, t}}-\psi_{4} \frac{z_{j, t-1}^{u}}{\bar{z}_{t-1}^{u}}, \bar{\pi}_{J, t}=\sum_{j} \pi_{j, t} \tilde{z}_{j, t-1} \\
& \tilde{z}_{j, t}=\max \left(\tilde{z}_{j, t-1}\left(1+\chi \frac{\bar{\pi}_{J, t}-\pi_{j, t}}{\bar{\pi}_{J, t}}\right), \tilde{z}_{J}\right)
\end{aligned}
$$

The assigned market shares are divided by the sum of the assigned market shares $\tilde{z}_{J, t}$ to calculate the adjusted assigned market share $\tilde{z}_{j, t}^{d}$. This is done to make sure that the sum of the adjusted assigned market share is 1 , even though we introduced a minimum assigned market share.

$$
\tilde{z}_{j, t}^{d}=\frac{\tilde{z}_{j, t}}{\tilde{z}_{J, t}}
$$

Afterwards, the nominal demand is distributed among the firms in a two-step procedure. In the first step, each firm encounters an assigned nominal demand $z_{j, t}^{d}$, which is a share of total nominal demand. It is calculated by multiplying the adjusted assigned market share $\tilde{z}_{j, t}^{d}$ with the total nominal demand $z_{J, t}^{d}$, the latter being the sum of the funds of all workers.

$$
z_{j, t}^{d}=\tilde{z}_{j, t}^{d} z_{J, t}^{d}
$$

Firms then try to satisfy all of the demand which is allocated to them in the first round. Their ability to do so is calculated by multiplying their supply $s_{j, t}$ with their price $p_{j, t}$. If they are not able to meet their assigned nominal demand, the remaining demand is allocated to those firms who still have supplies left. This accounts for consumers who encounter empty shelves and go to shops where they hope to find consumption goods left.

The following equation reads as follows: The sales of the firm $\mathrm{j} z_{j, t}$ is equal to the (a) assigned nominal demand, if the firm's assigned nominal demand equals its ability to satisfy demand, (b) its ability to satisfy demand, if the assigned nominal demand is larger and (c) its assigned nominal demand plus the individual share of the ability to

\footnotetext{
7 Notice that the formula slightly differs from Dosi et al. $(2006,17)$ and the subsequent models. When we tested the original formula, we realized that since competitiveness is strictly negative, the formula had the opposite effect, i.e. more expensive firms and firms that cannot meet their demand gained a higher market share. This seems not to be the case in Dosi et al. (2019b), where the original formula is also employed, but the competitiveness factor is calculated in a different way to be strictly positive. We also normalized price and unsatisfied demand in the calculation of competitiveness, since unsatisfied demand is otherwise much more important for competitiveness than pricing due to the different scales. Maybe the apparent error in the original formula did not attract attention, because firms with a lower price tend to have higher unsatisfied demand and subsequently saw an increase in their market share anyway.
} 
satisfy futher demand multiplied with either the total ability to satisfy further demand $z_{J, t}^{r}$ or the total unsatisfied demand $z_{J, t}^{u}$, whichever is lower.

The rest of the equations are needed to describe the exact technical specification: First, the unsatisfied sales $z_{j, t}^{u}$ are calculated for each firm as the difference between the assigned nominal demand and their supply times their price. It is only part of the total unsatisfied sales, however, if the difference is positive. If the difference is, on the other hand, negative, then the difference between their ability to satisfy demand and their assigned nominal demand (i.e. $-z_{j, t}^{u}$ ) is their ability to satisfy further demand $z_{j, t}^{r}$. Total sales $z_{J, t}$ are given by summing up all individual sales.

$$
\begin{aligned}
& z_{j, t}= \begin{cases}z_{j^{\star}, t}^{d} & \text { for } j^{\star}: z_{j^{\star}, t}^{u}=z_{j^{\star}, t}^{d}-s_{j^{\star}, t} p_{j^{\star}, t}=0 \\
s_{j^{\prime}, t} p_{j^{\prime}, t} & \text { for } j^{\prime}: z_{j^{\prime}, t}^{u}=z_{j^{\prime}, t}^{d}-s_{j^{\prime}, t} p_{j^{\prime}, t}>0 \\
z_{j^{\circ}, t}^{d}+\frac{z_{j^{\circ}, t}^{r}}{z_{J, t}^{r}} \min \left(z_{J, t}^{r}, z_{J, t}^{u}\right) & \text { for } j^{\circ}: z_{j^{\circ}, t}^{u}=z_{j^{\circ}, t}^{d}-s_{j^{\circ}, t} p_{j^{\circ}, t}<0\end{cases} \\
& z_{J, t}^{r}=\sum_{j^{\circ}} z_{j^{\circ}, t}^{r}, z_{j^{\circ}, t}^{r}=-z_{j^{\circ}, t}^{u} \forall j^{\circ} \in\left\{j \mid z_{j, t}^{u}<0\right\} \\
& z_{J, t}^{u}=\sum_{j^{\prime}} z_{j^{\prime}, t}^{u} \forall j^{\prime} \in\left\{j \mid z_{j, t}^{u}>0\right\}, z_{J, t}=\sum_{j} z_{j, t}
\end{aligned}
$$

\subsubsection{Profits and Taxes}

Profits $\Pi_{i, t}$ and $\Pi_{j, t}$ are sales minus costs. For capital good firms i, sales are the price of the machine sold in the current period $p_{i, t}^{k}$ multiplied with the sum of machines sold by $\mathrm{i}$ to each consumption good firm $\mathrm{j} k_{i, j, t}^{d e l}$. Cost consist of wage payments and interest paid on debt $a_{i, t}$. The interest rate is given by $\omega_{4}$. The wage payments are the sum of the wage rates of each employee $w_{h^{\star}, t}$, where $h^{\star}$ denotes the engineers and administrators employed by the specific capital good firm.

$$
\Pi_{i, t}=p_{i, t}^{k} \sum_{j} k_{i, j, t}^{d e l}-\omega_{4} a_{i, t}-\sum_{h^{\star}} w_{h^{\star}, t} \mid \forall h^{\star} \in\{\text { all m and n employed by } i\}
$$

Sales of consumption good firms are given by $z_{j, t}$ (as calculated in the previous subsection). Consumption good firms $\mathrm{j}$ also pay interest and wages (in their case for the laborers and administrators they employ), but additionally have to take the depreciation of their capital stock into account. We assume that the initial booking value of each machine is given by its price $p_{k}$ and that it then depreciates linearly over its maximum lifetime $\phi^{\max }$.

$$
\Pi_{j, t}=z_{j, t}-\omega_{4} a_{j, t}-\frac{\sum_{k_{j}} p_{k}}{\phi^{\text {max }}}-\sum_{h^{\star}} w_{h^{\star}, t} \mid \forall h^{\star} \in\{\text { all } 1 \text { and m employed by } j\}
$$

After calculating their profits, firms pay a flat tax rate of $\omega_{3}$ on them. 


\subsubsection{Loans and Insolvencies}

For simplicity, we assume that a firm takes a loan whenever its deposits turn negative. Once its net debts exceed the maximum debt to sales ratio $z a^{\max }$, the firm is listed for insolvency. The same happens to firms who only operate at the minimum market share $\tilde{z}_{J}$. We adopted the assumption of Dosi et al. (2010) that the number of firms is fixed, but to account for stock-flow consistency, an insolvent firm is bailed out. This serves to avoid a situation in which we would need a deus ex machina (we commented on this in the discussion section). Firms that are bailed out are endowed with a new stock of debt and deposits in the inflationadjusted initial amount. They adapt their offered wage rate to the one average workers of a certain type get paid and plan their business expecting the market share that was assigned to them in the last period (at least $\underline{z}_{-}$).

\subsubsection{Wage Setting}

At the end of each period, firms adapt their wage offers according to a logic described in Sect. 4. Wages of the current staff are not updated automatically. Instead, only workers who bargain and unemployed workers looking for a job receive the new wage offer.

\subsection{Workers}

Workers behave according to a very simple set of rules, which largely depend on the reservation wage that is set according to a rule specified in Sect. 4.2. Unemployed laborers/administrators/engineers apply to every job that matches their skill profile and offers a wage rate that is at least as high as the worker's reservation wage. Employed workers who are discontent with their pay as their reservation wage is above their actual wage rate, bargain with their employer and quit their jobs if they get an offer which is below their reservation wage. Workers use their funds, which are replenished by wages and unemployment benefits, to buy as many consumption goods as possible.

\subsection{Bank}

The banking sector is modeled as a bank who behaves as a rather passive agent: It provides firms with loans (see Sect. 3.1.8) and charges an interest rate $\omega_{4}$ on debts $a_{g, t}$. The debts of insolvent firms are listed as non-performing assets. The bank also stores any savings of workers and firms, but does not pay any interests. Profits made in the banking sector $\boldsymbol{\Pi}_{b a n k, t}$ are thus the sum of all interest charged on debts minus new non-performing assets. 


$$
\begin{gathered}
\Pi_{\text {bank,t }}=\omega_{4} \sum_{g^{\star}} a_{g^{\star}, t}-\sum_{g^{\prime}} a_{g^{\prime}, t} \mid \forall g^{\star} \in\{\text { all i,j not insolvent in } \mathrm{t}\} \\
\forall g^{\prime} \in\left\{\text { all i,j } \notin g^{\star}\right\}
\end{gathered}
$$

\subsection{Government}

The government is another passive agent that collects a flat tax rate $\omega_{3}$ on profits and pays unemployment benefits $w_{h, t}^{u}$ to workers, which are a fraction $\omega_{1}$ on their last wage. The latter is denoted with $w_{h, t-x}$, where $t-x$ is the period in which the worker was most recently employed.

$$
w_{h, t}^{u}= \begin{cases}\omega_{1} w_{h, t-1} & \text { if } \mathrm{h} \in\{1, \mathrm{~m}, \mathrm{n}\} \text { employed in } \mathrm{t}-1 \\ w_{h, t-1}^{u} & \text { if } \mathrm{h} \in\{1, \mathrm{~m}, \mathrm{n}\} \text { unemployed in } \mathrm{t}-1\end{cases}
$$

\section{Labor Market Institutions and Policies}

We want to study, how the agents in our artificial economy are affected by and react to different labor market institutions (modeled as ways in which workers set their reservation wage and firms set their wage offers) and policies starting from a benchmark scenario. ${ }^{8}$ Doing so helps us to uncover the driving forces of the model, but may also help us to identify — in a highly stylized way - the benefits and problems of such institutions and policies in the real world. Testing institutions individually and not in bundles has obvious drawbacks, as the amount of time needed for simulations increases dramatically with the number of possible combinations of policies and institutions. On the other hand, it allows us to single out the effects of each policy and institution, which due to the non-linear nature of our model may diverge in combinations with different other institutions and policies.

\subsection{Wage Setting Mechanisms}

We experiment with three different initial wage settings: $1-1-1,1-1.5-3,1-2-4$ (initial wages for laborers-administrators-engineers). We also explore two different wage setting mechanisms: Wages in the "Fordist" setting do not take the rate of unemployment into account and grow according to the growth of productivity. This setting could be imagined as a situation in which the trade unions are very powerful and want to make sure that the wage share remains constant. In this setting, firms raise their wage offers $w_{i / j, t+1}^{h}$ according to the growth in aggregate and individual

\footnotetext{
8 A similar approach was chosen by Dosi et al. (2010), although we allow for multiple deviations from the benchmark scenario at once. While our "Fordist" and "Competitive" (reservation) wage setting mechanisms closely follow Dosi et al. (2017) in name and logic, they are not per se combined with other rules regarding e.g. labor market flexibility
} 
productivity, which are weighted with the parameters $\psi_{1}$ and $\psi_{2}$. The wage offers are denoted with $t+1$, because they are calculated at the end of the period to be effective for the next period (for workers, who bargain at the end of this period or are hired in the next period). Making the growth of wages also dependent on the growth of individual productivity makes sure that firms, which are able to produce more efficiently, are also more likely able to recruit new staff on the labor market. Aggregate labor productivity $g_{t}$ is calculated by dividing the total output of the consumption good sector $q_{J, t}$ by the number of all workers employed in the economy (laborers $l_{J, t}$, administrators working in the in the consumption good sector $m_{J, t}$ and the capital good sector $m_{I, t}$, as well as engineers $n_{I, t}$ ).

$$
g_{t}=\frac{q_{J, t}}{l_{J, t}+m_{J, t}+m_{I, t}+n_{I, t}}
$$

Individual productivity for consumption good firms is given by the growth of laborer productivity of the capital stock designated for use, which is the inverse of the respective labor intensity, i.e. $\frac{1}{\bar{\lambda}_{j, t}^{l}}$. For capital good firms, the growth in individual productivity takes into account both the growth in laborer and engineer productivity and weights them according to the fixed payback parameter $\tau_{J}$ that firms use to evaluate machines (see the equation, where the cost factor is calculated, Eq. 2). The intuition behind this formula is the following: Consumption good firms have to pay the price, which is determined by the wage rate of engineers and the engineer intensity once. They plan to pay the runtime costs for the machine, which is given by the laborer intensity and the wage rate of laborers $\tau_{J}$ times. ${ }^{9}$ Rewriting the growth rate of the individual productivity of consumption good firms yields $\frac{\bar{\lambda}_{j, t-1}^{l}-\bar{\lambda}_{j, t}^{l}}{\bar{\lambda}_{j, t}^{l}}$. The growth rate of the individual productivities as perceived by capital good firms can be found mutatis mutandis. The wage offers are always at least as high as they were in the previous period.

$$
\begin{gathered}
w_{j, t+1}^{h}=\max \left(w_{j, t}^{h}, w_{j, t}^{h}\left(1+\psi_{1} \frac{g_{t}-g_{t-1}}{g_{t-1}}+\psi_{2} \frac{\bar{\lambda}_{j, t-1}^{l}-\bar{\lambda}_{j, t}^{l}}{\bar{\lambda}_{j, t}^{l}}\right)\right) \mid h \in\{l, m\} \\
w_{i, t+1}^{h}=\max \left(w_{i, t}^{h}, w_{i, t}^{h}\left(1+\psi_{1} \frac{g_{t}-g_{t-1}}{g_{t-1}}+\psi_{2}\left(\frac{\tau_{J}}{1+\tau_{J}} \frac{\lambda_{i, t-1}^{l}-\lambda_{i, t}^{l}}{\lambda_{i, t}^{l}}\right.\right.\right. \\
\left.\left.\left.+\frac{1}{1+\tau_{J}} \frac{\lambda_{i, t-1}^{n}-\lambda_{i, t}^{n}}{\lambda_{i, t}^{n}}\right)\right)\right) \mid h \in\{m, n\}
\end{gathered}
$$

In the "Market" setting, it is assumed that wage offers also react to unemployment. To model it very simply, the increase of the "Fordist" setting caused by the rise in

\footnotetext{
9 Both the price and the runtime costs actually also depend on administrator intensity and wage. Since the development of administrator intensity is directly linked to the development of laborer and engineer intensity, however, we abstract from this in the wage setting mechanism.
} 
aggregate output is multiplied with the employment rate of the respective type of worker, which is 1 minus the unemployment rate $v_{H, t}$, where $\mathrm{H}$ denotes the type of worker. ${ }^{10}$ This means that firms, which face full employment raise their wage offers according to the "Fordist" setting. If on the other hand one type of workers faces high unemployment, their wage offers will only grow slowly as firms do not perceive a necessity to increase their wage offers rapidly if competition among workers is high. As in the "Fordist" setting, wage offers can never be lower than they were in the last period.

$$
\begin{gathered}
w_{j, t+1}^{h}=\max \left(w_{j, t}^{h}, w_{j, t}^{h}\left(1+\left(1-v_{H, t}\right) \psi_{1} \frac{g_{t}-g_{t-1}}{g_{t-1}}+\psi_{2} \frac{\bar{\lambda}_{j, t-1}^{l}-\bar{\lambda}_{j, t}^{l}}{\bar{\lambda}_{j, t}^{l}}\right)\right) \\
\mid h \in\{l, m\} \\
w_{i, t+1}^{h}=\max \left(w_{i, t}^{h}, w_{i, t}^{h}\left(1+\left(1-v_{H, t}\right) \psi_{1} \frac{g_{t}-g_{t-1}}{g_{t-1}}+\psi_{2}\left(\frac{\tau_{J}}{1+\tau_{J}} \frac{\lambda_{i, t-1}^{l}-\lambda_{i, t}^{l}}{\lambda_{i, t}^{l}}\right.\right.\right. \\
\left.\left.\left.+\frac{1}{1+\tau_{J}} \frac{\lambda_{i, t-1}^{n}-\lambda_{i, t}^{n}}{\lambda_{i, t}^{n}}\right)\right)\right) \mid h \in\{m, n\}
\end{gathered}
$$

\subsection{Reservation Wage Setting Mechanisms}

As discussed in Sect. 3.2, the reservation wage $\underline{w}_{h, t}$ of a specific worker determines, whether or not an unemployed worker applies for a job or an employed worker wants to bargain for a higher wage. We tested two different mechanisms to set $\underline{w}_{h, t}$ : In the "Competitive" setting, employed workers expect their wages to grow from last period's wage $w_{h, t-1}$ by a fixed fraction $\omega_{2}$, which is a parameter. Unemployed workers, on the other hand, accept every job that offers a wage above their unemployment benefits $w_{h, t}^{u}$. This setting makes sure that labor market frictions are low-employed workers basically try to bargain in every period and unemployed workers are very likely to take up jobs.

$$
\underline{w}_{h, t}= \begin{cases}\left(1+\omega_{2}\right) w_{h, t-1} & \text { if employed } \\ w_{h, t}^{u} & \text { if unemployed }\end{cases}
$$

In the "Market" setting, workers react to the situation they perceive at the labor market. They think of the labor market as a lottery with two possible outcomes: With a probability given by the rate of employment $1-v_{H, t}$ they expect to find a job that pays not only their last wage (which is their actual or-if they are employed-potential unemployment benefit $w_{h, t}^{u}$ divided by the unemployment benefit rate $\omega_{1}$ ), but

\footnotetext{
${ }^{10}$ If substitution is enabled, only the rate of employment at the lowest possible skill level is taken into account.
} 
also a raise amounting to the growth rate of the aggregate labor productivity $g_{t}$. With the complementary probability (the rate of unemployment $v_{H, t}$ ), however, they estimate to end up unemployed and collect unemployment benefits $w_{h, t}^{u}$. The reservation wage is then given by the expected payoff of the lottery.

$$
\underline{w}_{h, t}=\left(1-v_{H, t}\right) \frac{w_{h, t}^{u}}{\omega_{1}}\left(1+\frac{g_{t}-g_{t-1}}{g_{t-1}}\right)+v_{H, t} w_{h, t}^{u} \mid h \in\{l, m, n\}
$$

\subsection{Substitution and Upskilling}

We experimented with (limited) substitution, allowing workers to work in a job that is one level below their skill level as well (i.e. administrators may work as laborers and engineers may work as administrators). We finally allowed for upskilling: A certain percentage $(0 \%, 0.5 \%, 1 \%$ or $1.5 \%)$ of unemployed workers of a certain type raises their skill level at the end of each period (i.e. unemployed laborers may become administrators and unemployed administrators may become engineers).

\section{Results}

We also follow the tradition of Dosi et al. (2010) in the analysis of our model. Due to the fact that it depends on stochastic processes and non-linear interactions between heterogeneous agents, we are not able to fully analyze its properties analytically. Instead, we ran Monte Carlo simulations starting from a base line model in order to test the results of various different labor market institutions and policies with the help of means and gam (generalized additive model) regressions. This approach may be considered to be problematic, as an important feature of our model is its pathdependency. By testing different labor market institutions and initial values, however, we can get a grip on what determines the direction of this path apart from pure chance. The Monte Carlo simulations are run with fixed random seeds and are thus reproducible. ${ }^{11}$ We analyzed our results and visualized our data using the programming language $\mathrm{R}$ (R Core Team 2013) with the packages ggplot2 (Wickham 2009) and lattice (Sarkar 2008). The initial parameters of the simulation are found in "Appendix" (see Tables 1 and 2) and are set according to the original Keynes + Schumpeter model by Dosi et al. (e.g. 2010), except for the new parameters regarding the introduction of heterogeneous labor in the form of laborers, administrators

\footnotetext{
${ }^{11}$ We ran 50 simulation for each configuration up to period 250 and then cut out the first 50 periods. We also simulated the baseline setup up to period 1050 and confirmed the validation results. Looking at such ultra-long periods, however, would not only draw the attention away from the medium-term reaction of the model to different initial parameter settings, but also require an ultra-long term view of the economy involving the creation of new industries and skills and thus seems inappropriate for this model.
} 


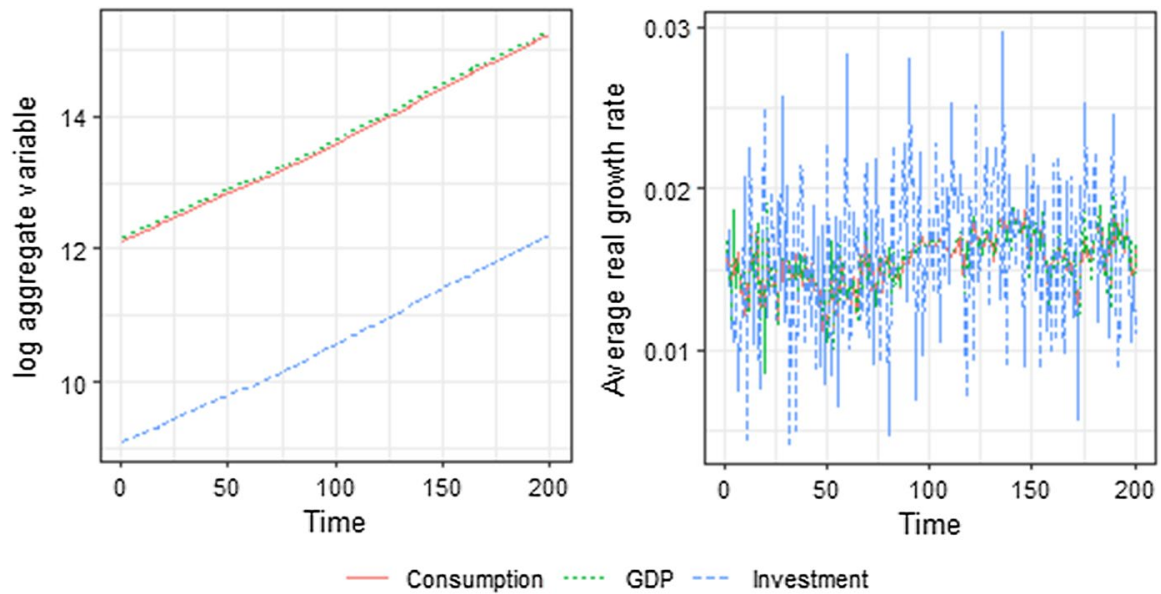

Fig. 2 Development of log aggregate levels (left) and growth rates (right) at initial wages of 1-1-1 (initial wages for laborers-administrators-engineers) (means). In line with the empirics, investment fluctuates more than GDP and consumption

and engineers and the fact that we cut the agent population by $50 \%$ due to restrictions in simulation capacity. ${ }^{12}$

\subsection{Validation}

Creating a complex model is not an end in itself, but a means to achieve results which resemble the real world more closely (i.e. fare better in a validation procedure). Following Dosi et al. (2010), we propose a validation of the model based on its ability to replicate stylized facts (SF) that can be observed empirically in the real world. Like the other models of the $\mathrm{K}+\mathrm{S}$ family, our model produces endogenous real growth of GDP, consumption and investment (SF1) with persistent fluctuations and business cycles (SF2, see Fig. 2).

Our model also replicates the Phillips curve (SF 3) (see Phillips 1958) and Beveridge curve (SF 4) (see Dow and Dicks-Mireaux 1958, 592) (see Fig. 3) and the corresponding shifts of the curves in the face of a change in structural unemployment. The model also meets three of Kaldor's initial stylized facts: the capital/output ratio remains constant, but the output/worker ratio rises, as the capital intensity (i.e. the capital/worker ratio) increases steadily over time (SF 5) (see Kaldor 1957, 592).

More importantly, our model produces wage inequality (SF 6) (e.g. Autor 2014), job polarization (SF 7) (e.g. Goos and Manning 2007; Goos et al. 2009) and wage polarization (SF 8) (e.g. Autor and Dorn 2013; Autor 2015) (see Fig. 4).

Those tendencies can be attributed to skill-biased technological change (SF 9) (e.g. Autor et al. 1998). The relative labor intensities of administrators [for

\footnotetext{
12 We found out that the output of the model does not change qualitatively by doing that or even reducing it to e.g. $20 \%$, which makes this move not only convenient, but also appropriate.
} 

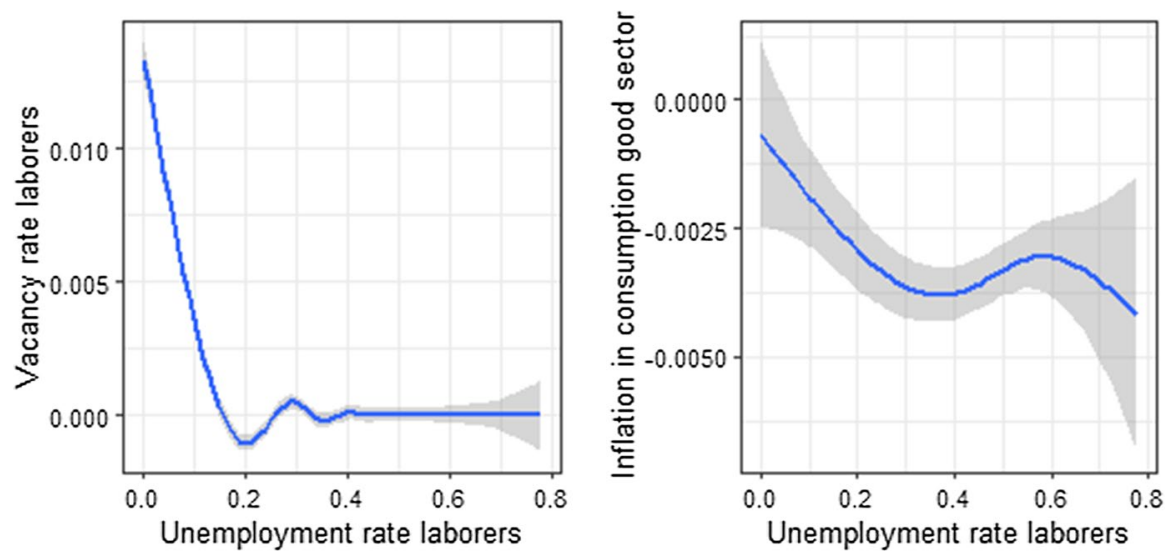

Fig. 3 Beveridge curve (left) over all initial wages and Philipps curve (right) for laborers at initial wages of 1-1-1 (generalized additive model with standard error)
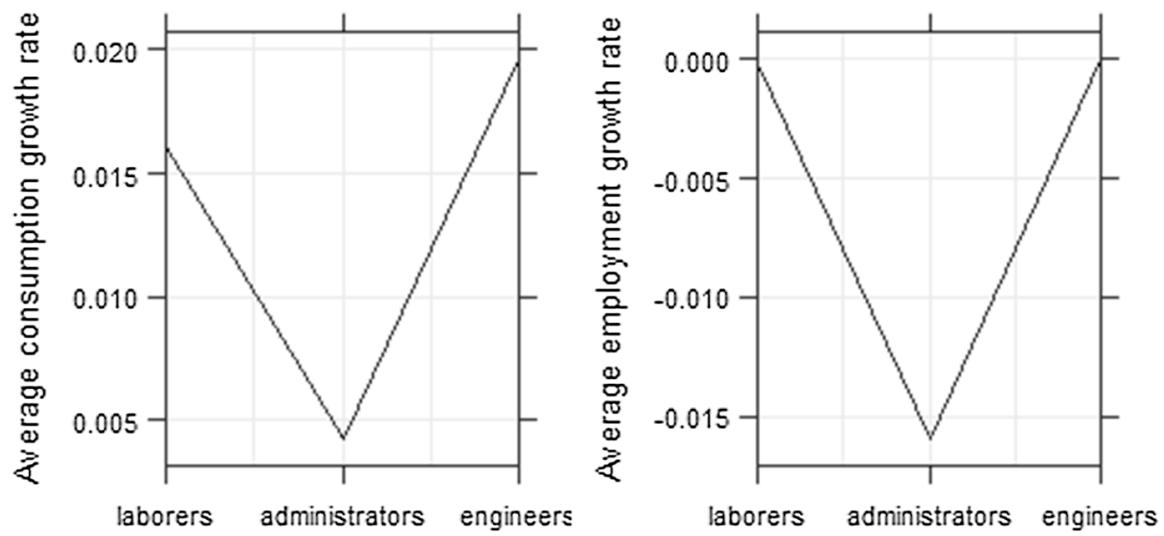

Fig. 4 Average growth rate of real consumption of employed workers (left) and average growth rate of employment (right) at initial wages 1-1-1 (means)

technical reasons, see Autor et al. (2003)] and laborers (for economic reasons) experience a decline. Since the employment of laborers is constrained by the number of machines available (and their labor intensities) and the employment of administrators by the number of employed laborers and engineers, both types of workers are affected by technological unemployment (SF 10) (see Frey and Osborne 2017). The changes in employment then translate to changes in relative wages (see Autor and Dorn 2013; Autor 2015). We thus see very interesting feedback effects: relative wages influence relative intensities through the innovation process, which then lead to differing rates of unemployment, which in turn influence relative wages (see Fig. 5). 

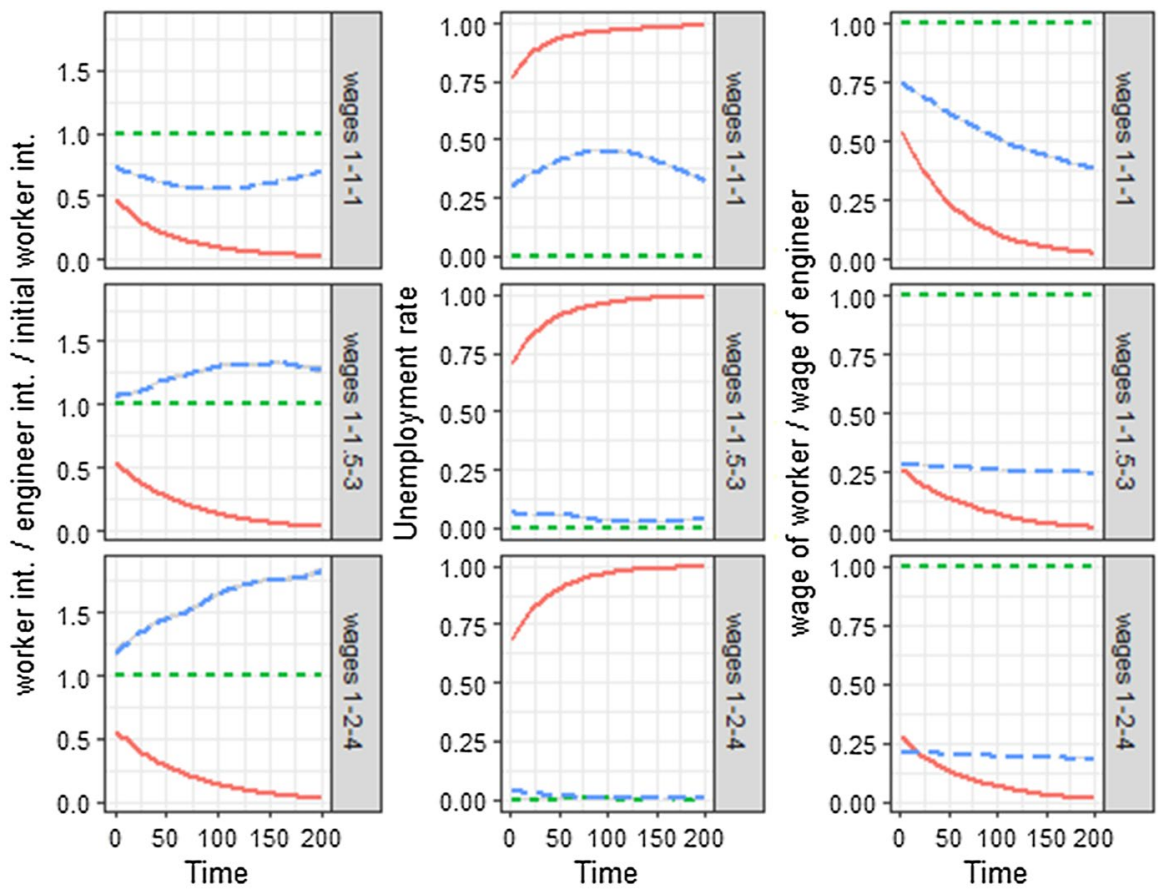

administrators

engineers

laborers

Fig. 5 Relative labor intensity (left), unemployment rate (middle) and wages (right) at different initial wage settings. A value of one in the left graph indicates that the initial number of engineers is enough to create jobs for all workers of the corresponding type in the long run. A value of one in the right graph indicates that the wage is equal to the average engineer. (generalized additive model with standard error)

\subsection{Policy Experiments}

Once we established the fact that our model actually produces the tendencies that we are interested in, albeit in a stylized way, we can now proceed to test different labor market institutions and policies. The goal of this exercise is to get aware of how wage inequality and polarization develop in different settings, whether they are harmful or beneficial and what could be done against them - at least within the limitations of our model. All following graphs show generalized additive models of 50 simulation runs for each configuration and their respective standard errors at each point in time.

\subsection{1 (Reservation) Wage Setting Mechanisms}

We begin our policy experiments by testing the different (reservation) wage setting mechanisms. The highest expectations are held, of course, for the "Fordist" wage 


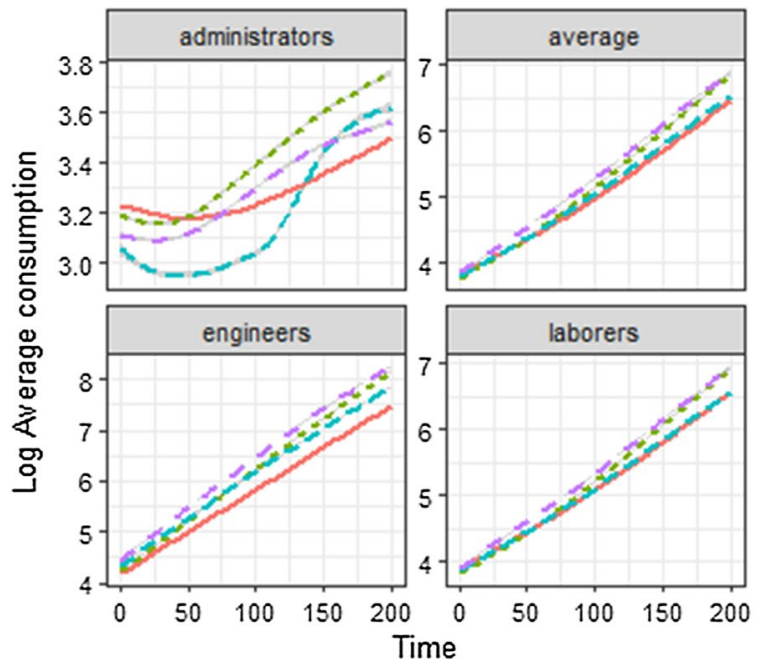

Fordist w., Competitive r.w.

Market w., Competitive r.w.

Fordist w., Market r.w.

Market w., Market r.w.

Fig. 6 The development of average consumption of different types of workers over time at initial wage setting 1-1-1

setting mechanism as one could expect that if we start with equal wages and wages grow with productivity, inequality would be low. But if we look at the average worker of a certain skill, the "Market" wage settings lead to the only Pareto efficient outcomes (i.e. it would be possible to make the average laborer and administrator better off by switching from the "Fordist" to te "Market" wage setting mechanism, without making the average engineer worse off). While the "Competitive" reservation wage setting mechanism provides the best outcome for administrators, the "Market" reservation wage setting mechanism is best for engineers. As we can see from the total average consumption, the "Market" settings do not only redistribute, but also cause an increase in GDP (see Fig. 6).

This is result is contrary to the Dosi et al. models, where the "Fordist" wage setting mechanism typically ensures a "twofold virtuous cycle" ( Dosi et al. 2019a, 8) in which increases in productivity translate to wage increases, which then increase aggregate demand, which feeds back to investment and employment creating more aggregate demand and so on. If we dig a little deeper into the data, we can see what drives our results:

At initial wages $1-1-1$, laborers labor is perceived to be relatively expensive, thus those inventions which save more laborers labor are favored compared to those which save more engineer labor. This tendency can be observed in Fig. 7, which shows the development of relative labor intensities of different types of workers to engineer intensity. While relative engineer intensity is by definition 1, relative laborers and administrator intensities are far below their initial settings. The latter can be attributed to the technological bias, but we are more interested in the economic bias concerning the former.

The main difference between the "Fordist" and the "Market" wage setting is now that the relative laborer intensity starts to rise again at a certain point in the 


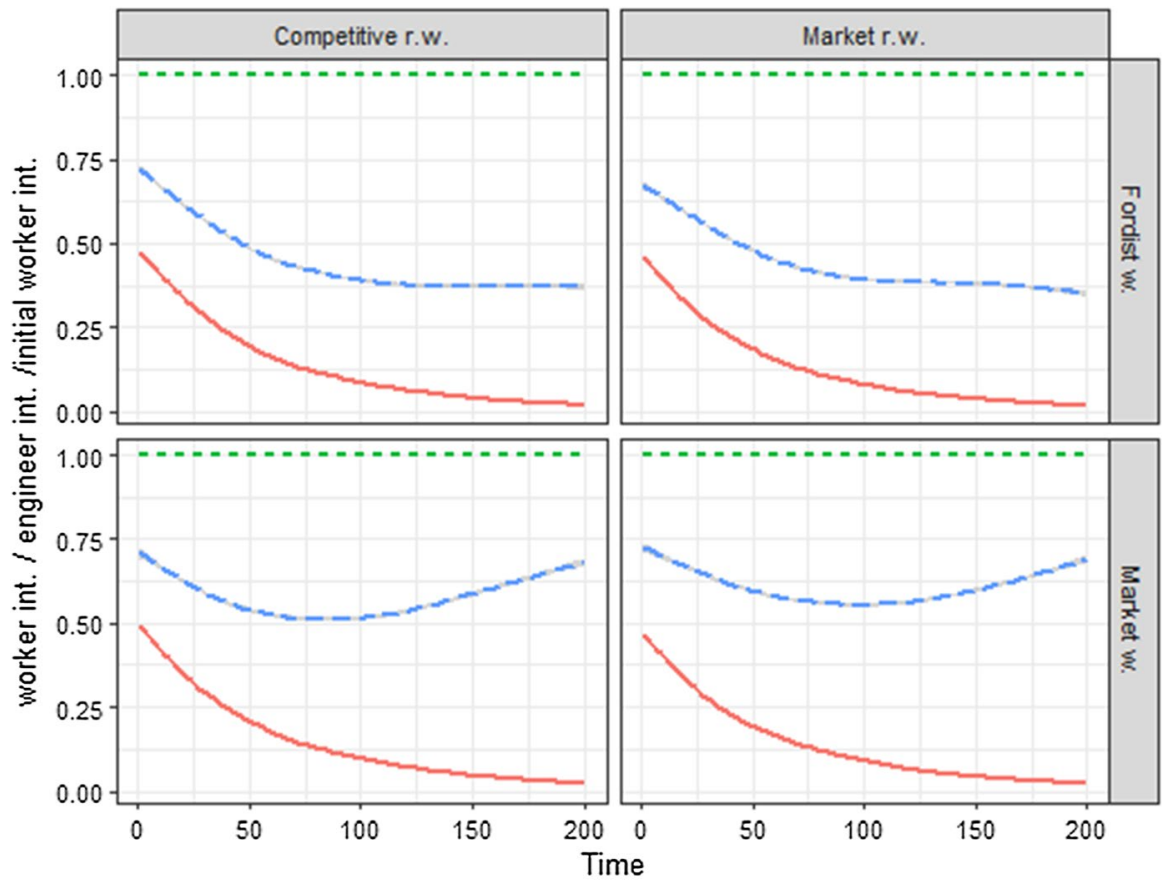

Fig. 7 The development of relative labor intensities of different types of workers over time at initial wage setting 1-1-1

"Market" setting, but stays at a low level in the "Fordist" setting. This aspect can be attributed to unemployment and how wage setting is influenced by it: Both wage setting mechanisms lead to high rates of unemployment among laborers (see Fig. 8). In contrast to the "Fordist" setting, the "Market" wage setting allows firms to adapt their wage offers to the excess supply. They will thus be relatively lower (see Fig. 9), which feeds back to the technological development that makes a turn around. In the end, unemployment of laborers will go down again.

As we can see in Fig. 10, the development in offered wages is only partly reflected in the development of actual wages. In the "Market" reservation wage setting, workers who are confronted with a high unemployment rate in their respective skill level are rather timid and only seldom bargain. Therefore, the high relative wage offers can only be translated to high relative actual wages in the "Competitive" reservation wage mechanism. Although employed laborers also suffer from a difference between offered and actual wages, it is much higher for administrators, which explains the result seen in Fig. 6. As we can now differentiate between employed and unemployed workers, we see that the "Fordist" / "Competitive" combination is also Pareto efficient, as those administrators who have a job are very well off, leading to a high horizontal (within-group) inequality. 


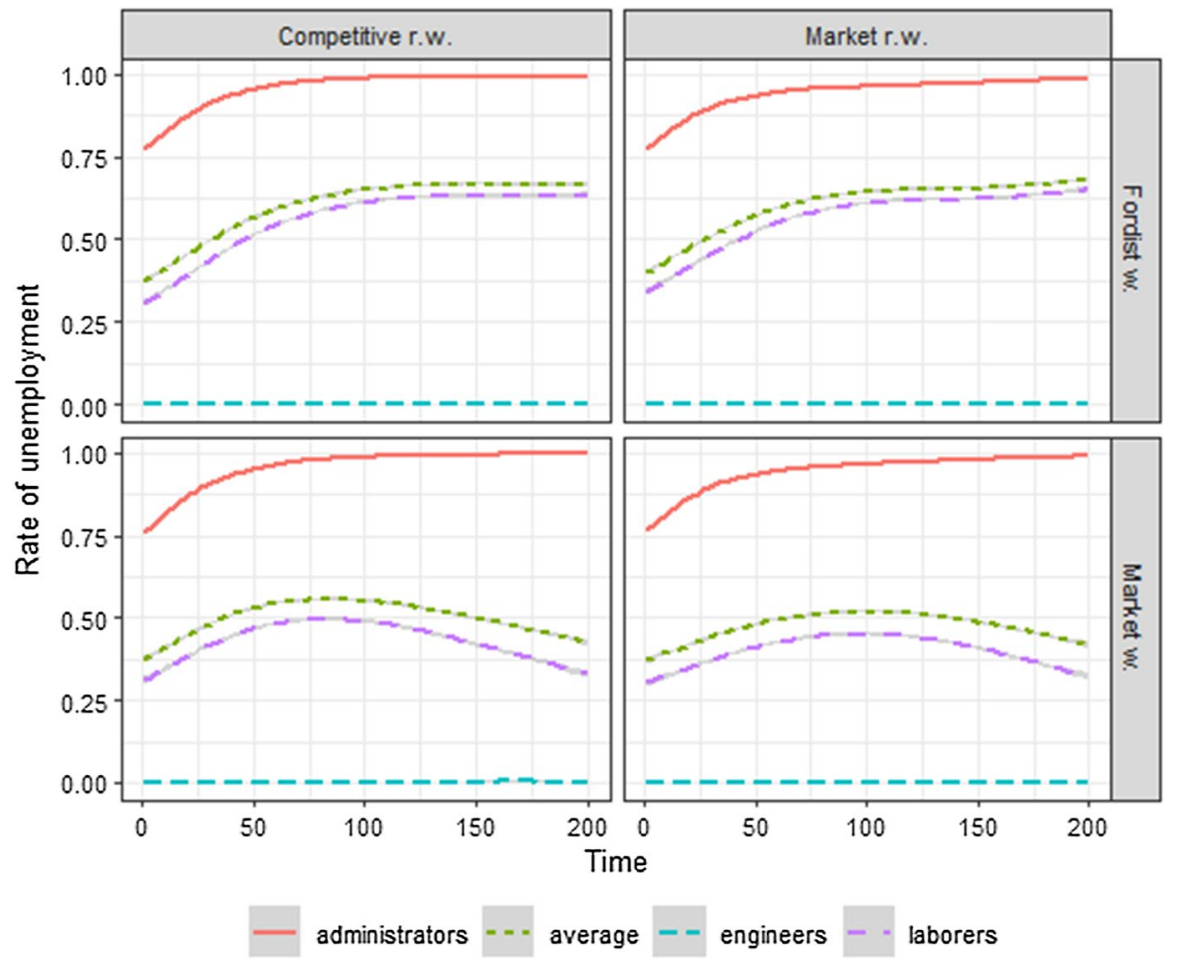

Fig. 8 The development of the rate of unemployment different types of workers over time at initial wage setting 1-1-1

The main finding of this comparison is that the firms cannot be "tricked" into relative prices they believe are wrong in the long term, as they have the power to influence relative labor demand via the channel of technological change. If they perceive the wages of laborers as too high, the innovation process will be skill-biased. This, in turn, leads to technological unemployment for laborers. In the "Market" wage setting mechanism, however, wages react to unemployment, which feeds back to the direction of technological change after some time. High relative wages then lead to high unemployment, which lowers relative wages and after some time also lowers unemployment. Lower unemployment hints to a situation in which the factors of production can be utilized more fully, which makes the "Market" wage setting in the end more efficient, at least for initial wage settings of 1-1-1.

\subsubsection{Initial Wage Settings}

This main finding does not change if we vary the initial wages. The performance of the "Fordist" setting drastically improves if we start with a skill premium. But all that the "Fordist" setting does is to cement a high level of inequality that already existed in the beginning (i.e. relative prices that firms think are correct). Laborers and the 


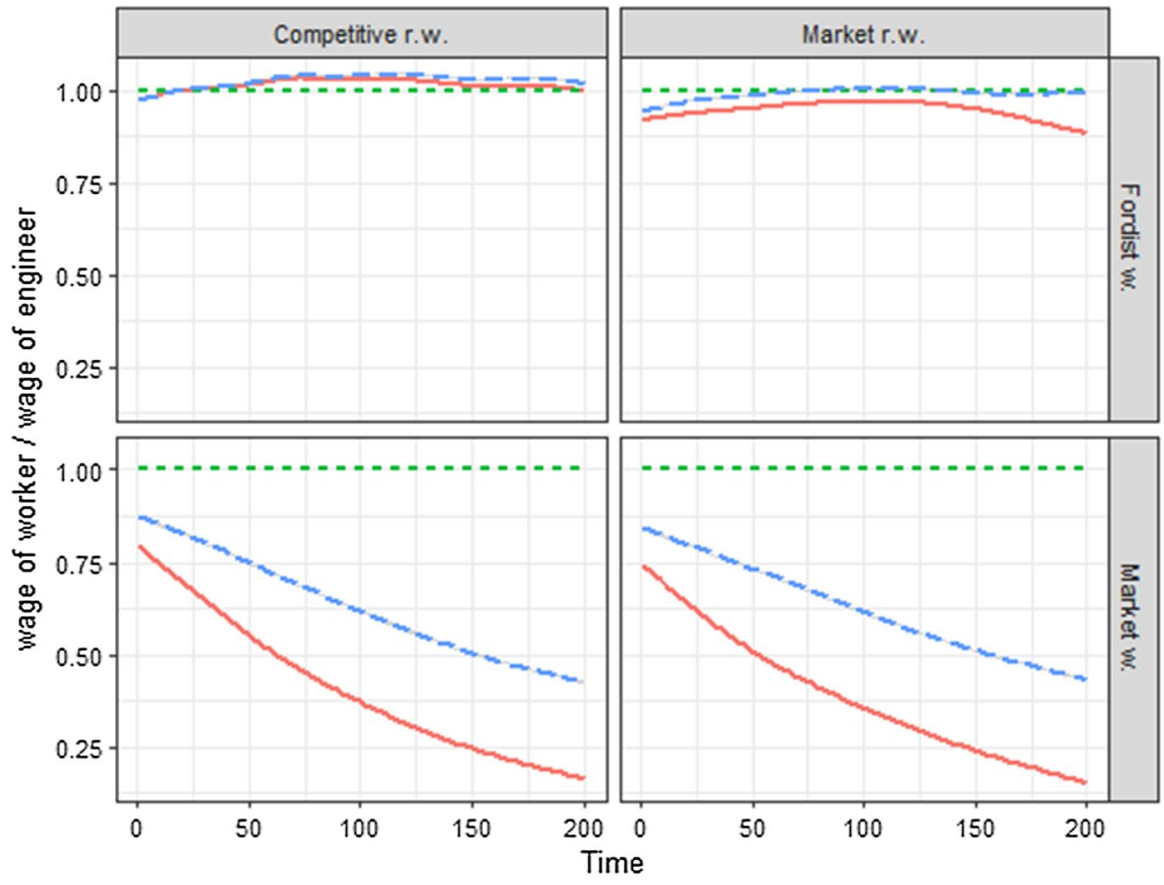

administrators

engineers - laborers

Fig. 9 The development of relative wage offers over time for different types of workers at initial wages 1-1-1. More specifically, this figure shows the wage rate an average employee of a certain type would get, if s/he bargained or got a new job in this period. Notice that in the "Fordist" wage setting, those offered wages are almost equal for any type of worker, since the wage offers do not react to unemployment

average population are best off at initial wages of 1-1.5-3 and 1-2-4, whereas engineers would on average achieve their highest level of consumption with the "Market" wage setting mechanism at initial wages of 1-2-4 (see Fig. 11).

This result seems to be peculiar, but it comes from the virtual full employment for laborers at 1-1.5-3 and actual full employment at 1-2-4 (see Fig. 12) which hints to a more even technological development in this setting (thus enabling a quasi-balanced growth path).

\subsubsection{Substitution and Upskilling}

So far, unemployed workers have very limited options to react to the situation at the labor market: They can only apply to jobs matching exactly their skill level. This is especially bad for administrators, as their jobs vanish. We now introduce substitution and upskilling. Those measures are very important, as they equip workers with the ability (within a certain limit) to adapt to the needs articulated at the market. This, in turn, changes the labor supply at the macro-level and thus 


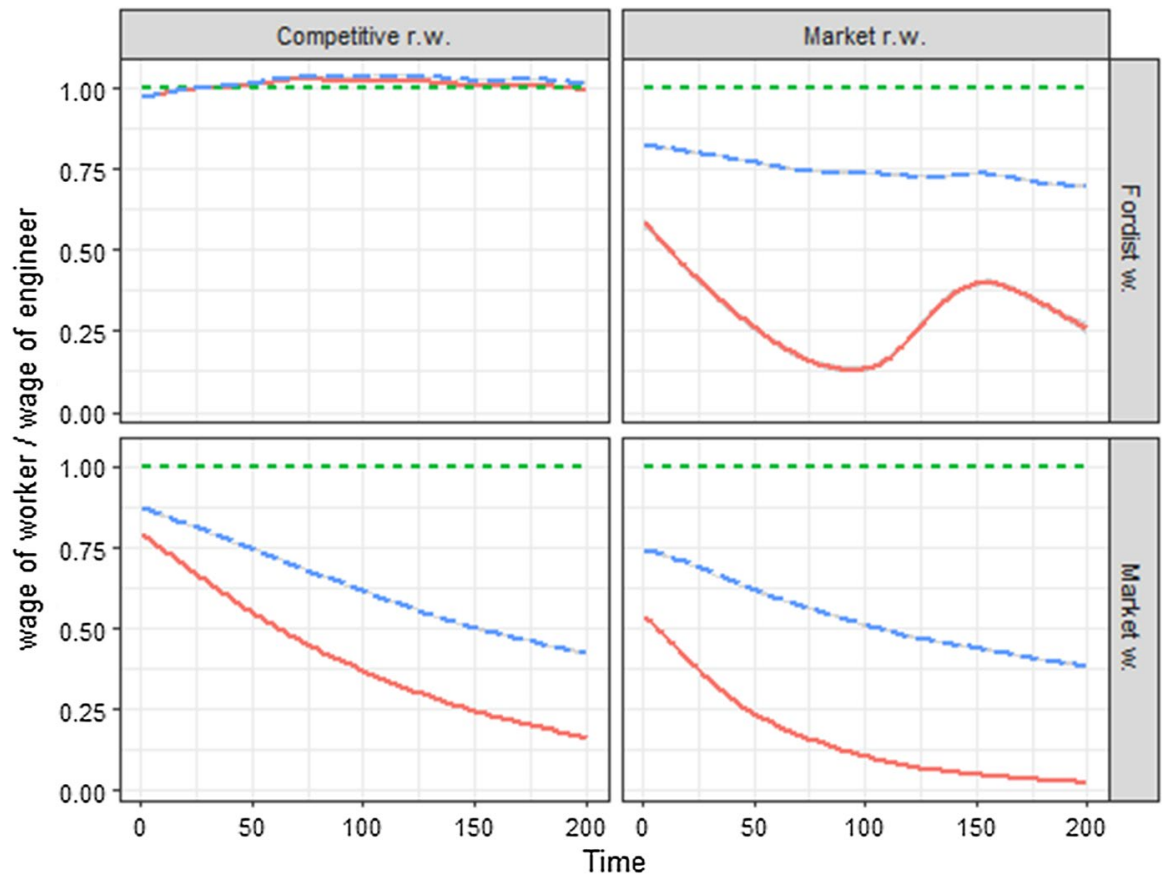

administrators - engineers - laborers

Fig. 10 The development of relative wages actually paid to different types of workers over time at initial wage setting 1-1-1

has a leveling impact on the balance of power between firms and workers, but also between workers of different skills. Although they are both targeting labor supply, Fig. 13 suggests that those measures have different effects for different types of workers: Enabling substitution mainly serves to eliminate the difference between administrators and laborers, as administrators start to pick up laborers jobs, which in turn leads to slightly lower consumption for laborers and slightly higher consumption for engineers. Upskilling, on the other hand, serves to raise the level of consumption of laborers. If substitution is enabled and upskilling set to $1.5 \%$ per period, we end up with only very low inequality. But upskilling is not a Pareto improvement (i.e. those who were engineers before will be worse off), as welfare gains resulting from a higher GDP are coupled with redistribution. The pie, so to speak, does not only get larger but each engineer receives a smaller share of it once they are more numerous.

The picture changes, however, if we analyze other initial wage settings than 1-1-1 (see Fig. 14). Upskilling is only able to combat some wage inequality in $1-1.5-3$, but almost none in 1-2-4. This result is, of course, crucially influenced by our assumption that only unemployed workers may upskill. Low levels of unemployment therefore translate into low levels of upskilling which perpetuates 

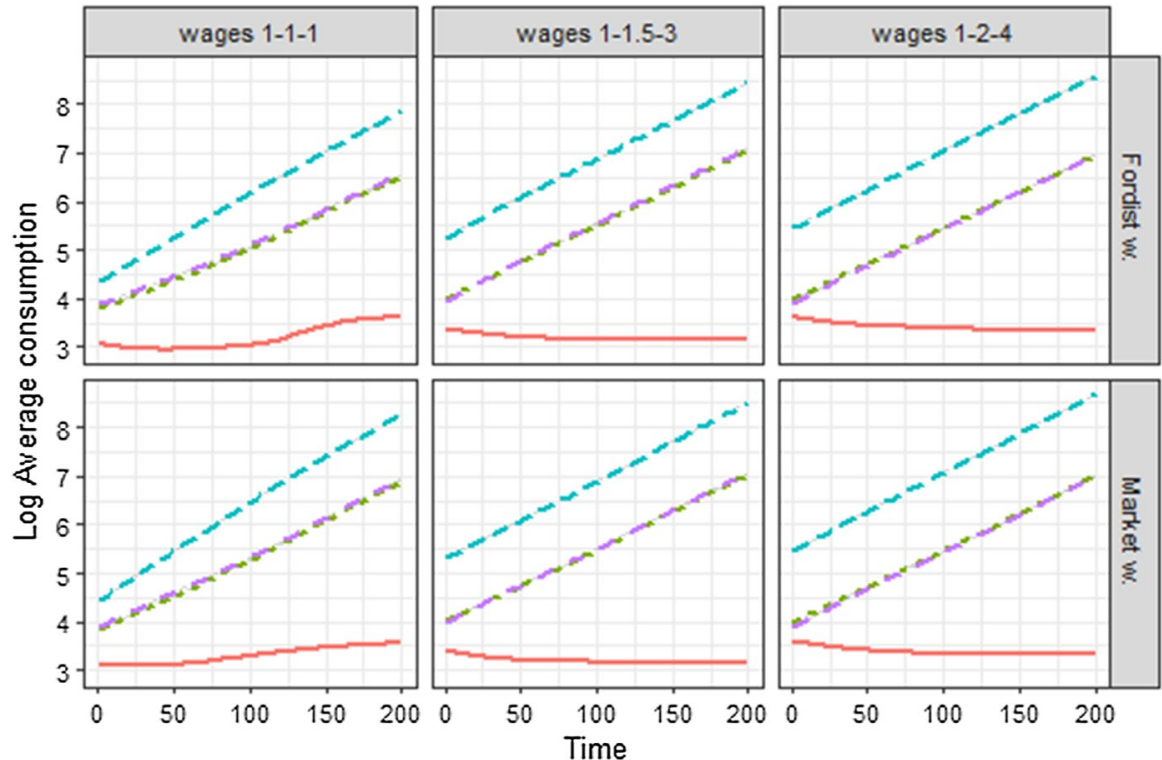

administrators

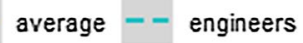

laborers

Fig. 11 The development of average consumption at "Market" reservation wage and different initial wage settings

the inequality that persists from the beginning (see Figs. 15, 16). Educative measures on its own are thus not enough to combat inequality, but must be combined with equalizing labor market policies. Together, they not only make sure that there are many "lovely jobs" (to use the terminology of Goos and Manning (2007)) and many people out there who are skilled enough to do them, but guarantee a decent standard of living for the rest of the population too.

\subsection{Discussion}

Our policy experiment results are partly in contradiction with the most advanced version of the general equilibrium directed technological change model to date as presented by Acemoglu and Restrepo (2018a). They, too, find that labor market rigidities (i.e. high relative laborers wages) lead to an excessive level of automation (i.e. a low relative laborers intensity). They also emphasize the role of raising the supply of highly skilled workers (i.e. upskilling). But they do not draw a connection between these topics. Our assumption that only unemployed workers are able to upskill is obviously simplified. One could also argue that a high wage premium also provides a high incentive to upskill (which would, of course, mitigate our results). It is obvious that workers need time to upskill and those who work full-time (and maybe have some childcare obligations, too) will find it very difficult to raise their 


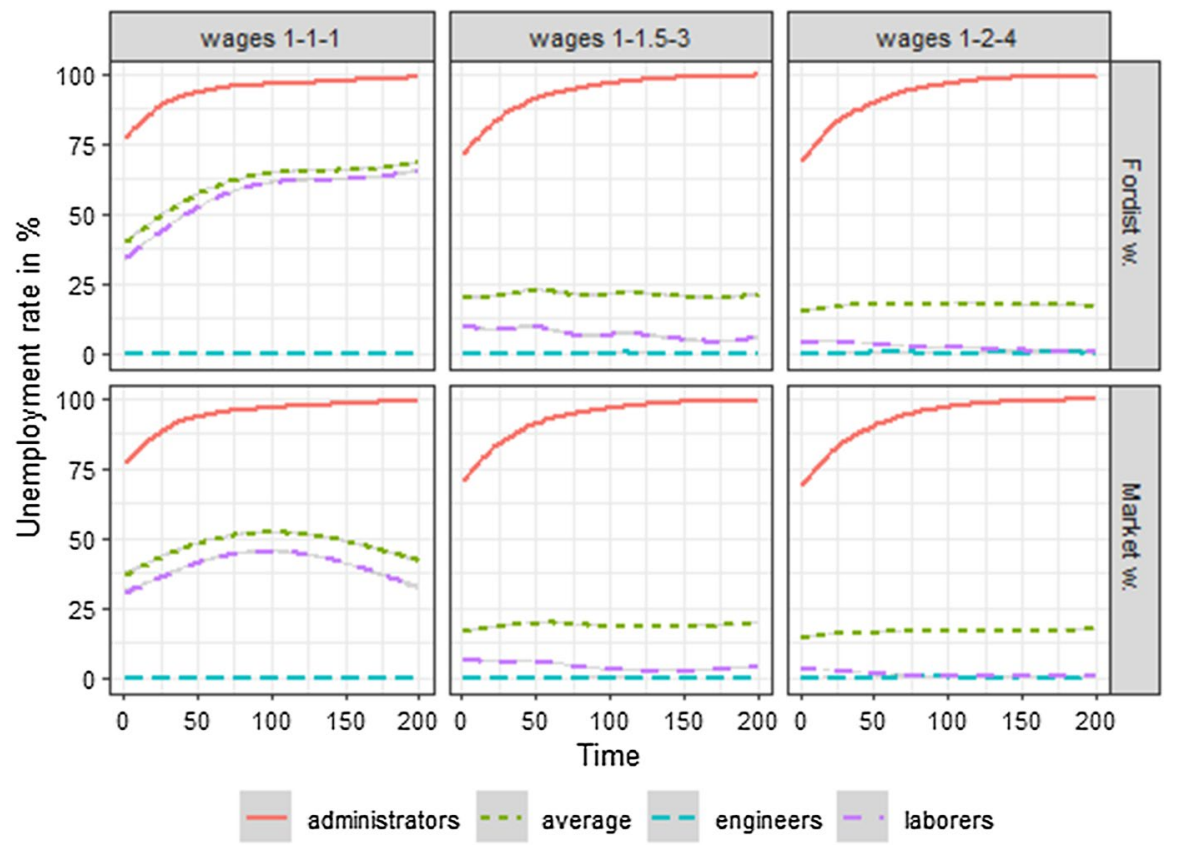

Fig. 12 The development of the rates of unemployment at "Market" reservation wage and different initial wage settings

skill (e.g. get a college education) in the evening or night. Thus, a certain trade-off between taking a low-skilled job and upskilling cannot be ignored. It is self-evident for young people on an individual level: Do I spend the next couple of years to get a college degree and benefit from a higher wage (or more fulfilling job) afterwards or do I take a job now? A scarcity of low-skilled jobs would have a huge impact on this decision. We think that it is worth studying this question in more detail in the future.

Even more importantly, our results suggest a different relationship between the share of higher-skilled workers and the wage premium than the Acemoglu-models of directed technological change. In the latter ones, higher skilled workers benefit from a higher number of peers. More high-skilled workers cause technological change to favour them even more. In our model, however, higher skilled workers actually benefit from lower upward education mobility.

Our results also contradict some of the conclusions drawn by Caiani et al. (2018). Technological change in our model does not affect capital productivity (which is assumed to be constant), but rather labor intensities (or, as Caiani et al. (2018) put it: the capital-labor-ratio). In our model, technological change therefore has a sustained impact on the relative demand for each type of worker that could not simply be overcome by an increase in the level of aggregate demand as it can be in their model. This could help to explain why wage inequality and polarization in fact flourished across institutional settings, albeit with different timing and speed.

While our model replicates a number of prominent stylized facts qualitatively, especially regarding the labor market, some other results do not reflect real world 


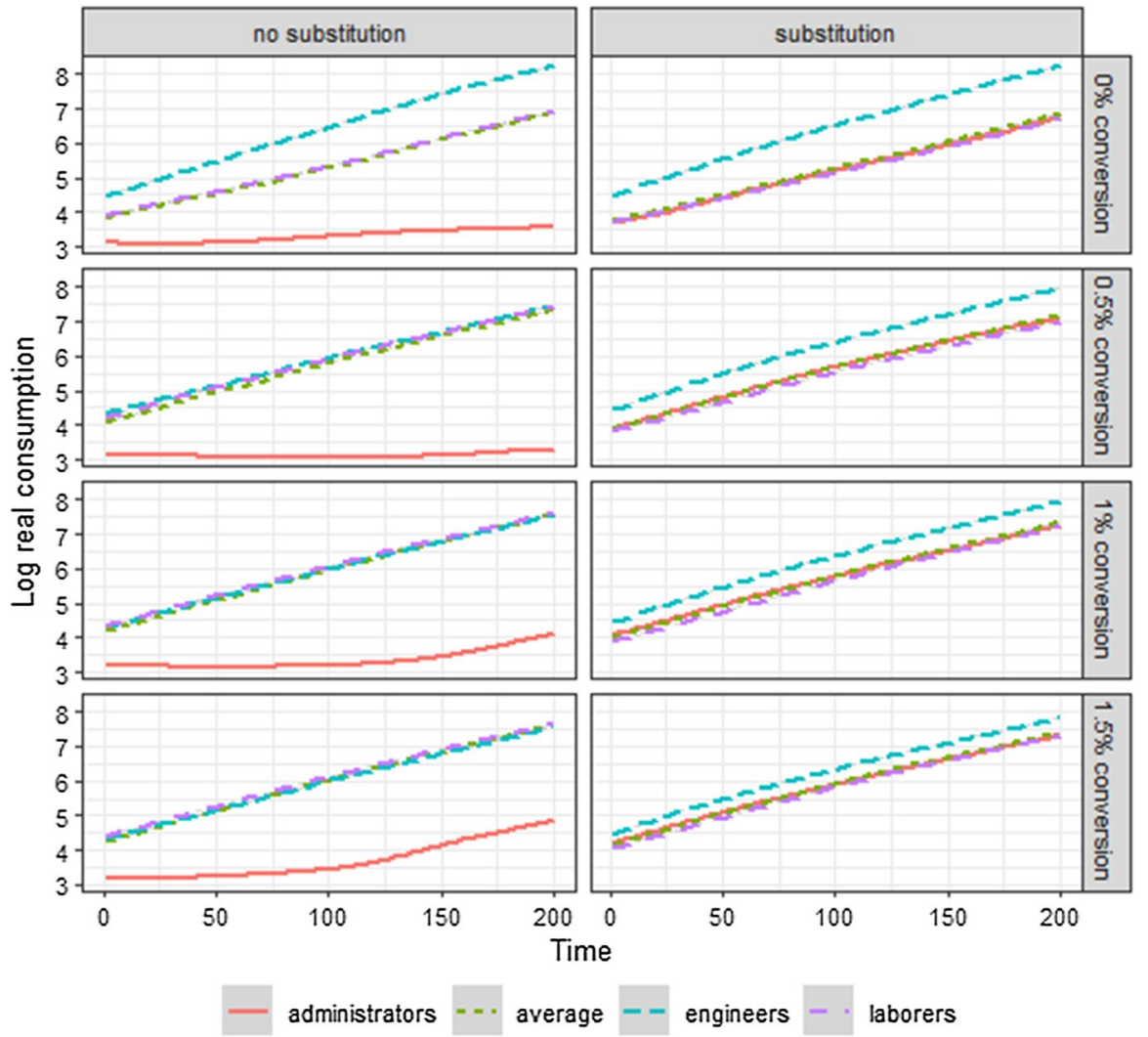

Fig. 13 The development of average consumption at "Market" wage and reservation wage settings, with initial wages 1-1-1 and different substitution/upskilling settings

data. This mainly concerns the pricing mechanism (and subsequently the levels of inflation, the distribution between capital and labor and the occurrence of crises) as well as industry evolution. We plan to overcome these problems in future versions of our model. We do not aim to quantitatively fit real data and thus refrain from inferring probabilities of certain outcomes or their magnitudes from our model.

The pricing mechanisms on the goods and labor markets partly react to excess supply, but not to excess demand. We experience excessive demand at the labor market for engineers, the consumption goods market and the capital goods market. The shortage of engineers leads to a situation in which capital good firms do not only compete on the goods market, but (even more importantly) on the labor market. Both wage setting mechanisms we explored favor more productive firms, thus our capital good sector monopolizes very quickly (it is a so-called winner-take-all market). The assumption that all capital good firms charge the same markup aggravates the situation, as less productive firms cannot decrease their markup to make their product more competitive (or vice versa, more productive firms do not raise their markup to reap surplus profits). On the other hand, this assumption makes it likely 


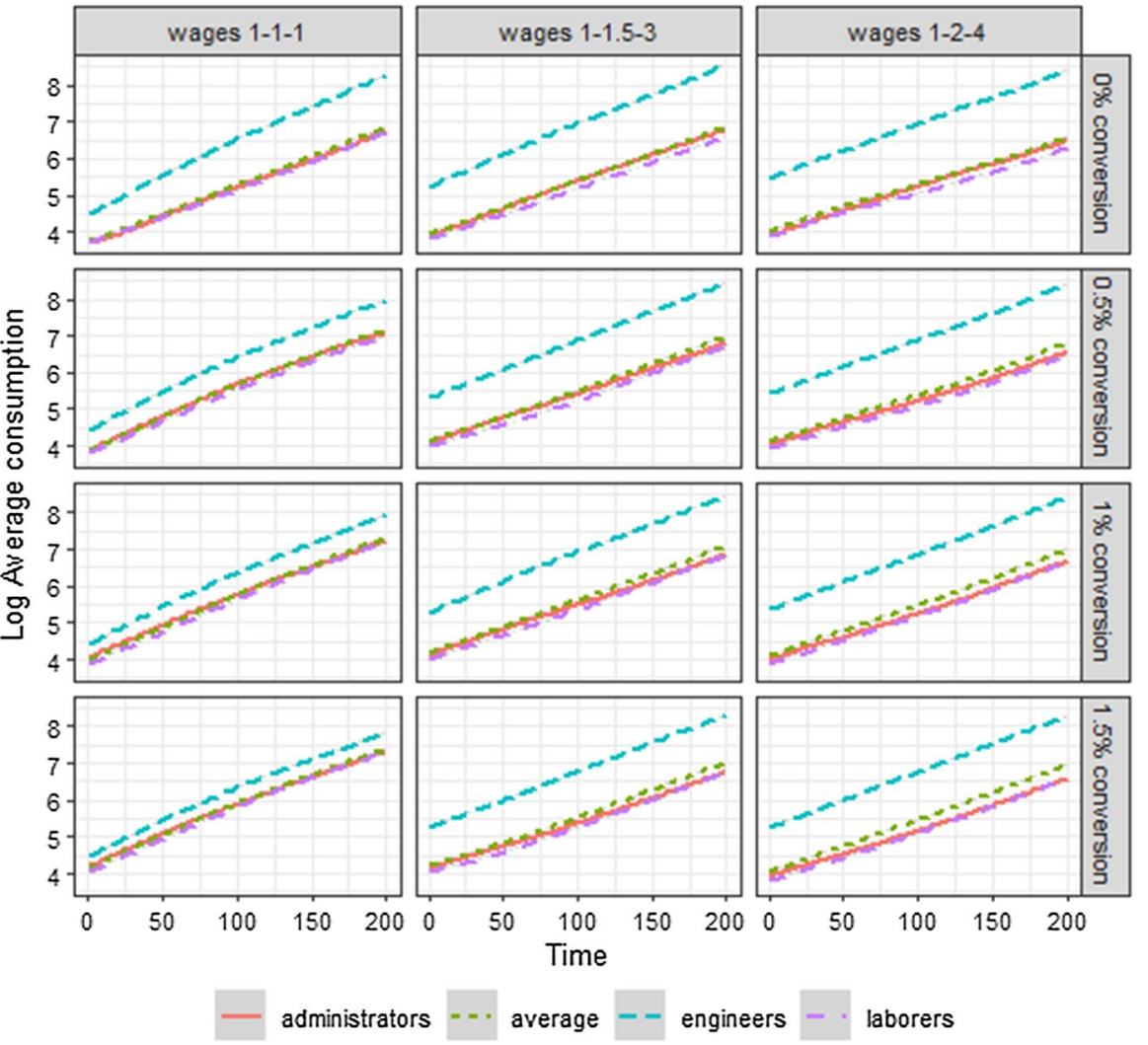

Fig. 14 The development of average consumption at "Market" wage and reservation wage settings, with substitution and different initial wage settings

that full monopolization is in fact one of the (or even the) most efficient possible outcomes, as all capital goods are produced by the monopolist who offers the cheapest one and does not exploit the situation.

A typical way out of this problem would be to allow for entrants. Since insolvent firms are bailed out in our model and try to re-enter the market, we do have de-facto entrants. Consumption good firms, which do not have any machinery left, try to buy new ones, which is why monopolization in the consumption good sector is not an issue. Capital good firms, however, only invest a fraction of past sales in R\&D. If sales in the last period were zero, the firm has thus no chance to catch up technologically. Possible ways to solve this problem include giving engineers the opportunity to become entrepreneurs and thus start their own firm or to fix a certain minimum expenditure (e.g. in terms of numbers of engineers) for R\&D.

We experienced similar issues regarding the pricing mechanism in the consumption good sector: here, as well, firms do not explicitly react to market-wide excess demand which may persist over long periods of time and therefore reduces the "Keynesian" properties of the model. The fact that investment is constrained by 


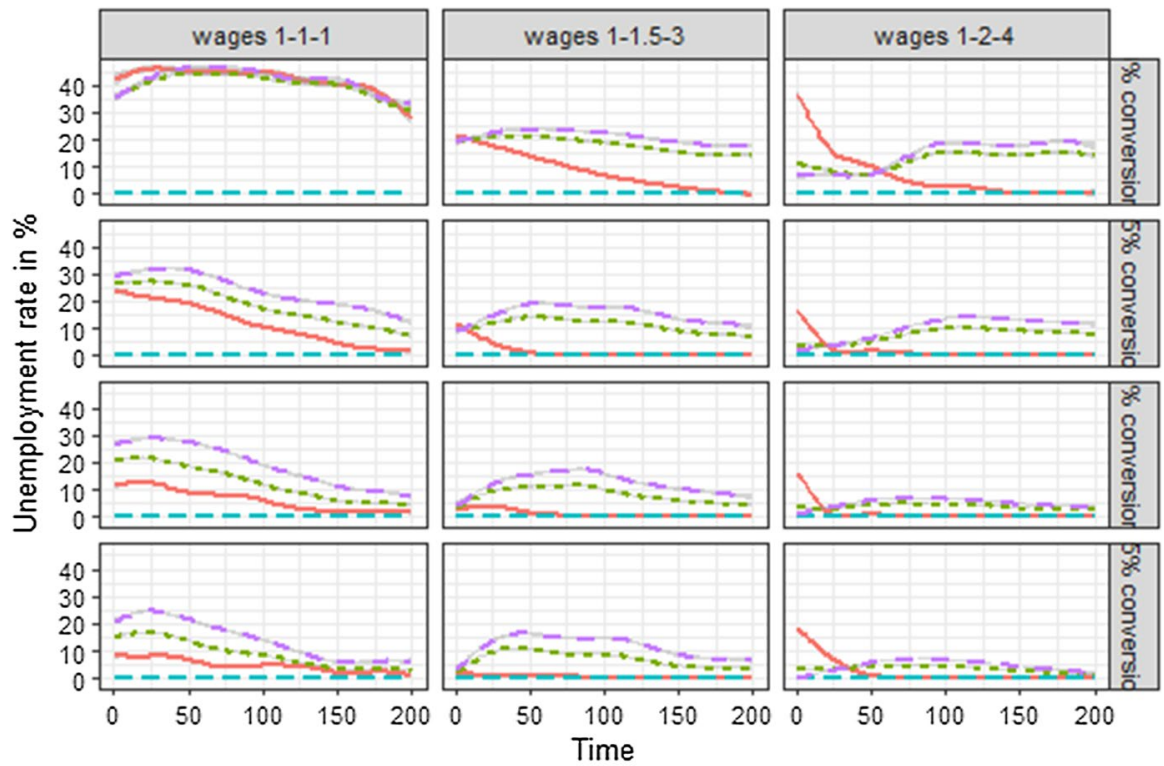

administrators - - average -- engineers - laborers

Fig. 15 The development of the rate of unemployment at "Market" wage and reservation wage settings, with substitution and different initial wage settings

supply of engineers contributes to that dynamic as the levels of investment can be expected to be smoothed. ${ }^{13}$ At the same time, however, the restriction of labor supply of highly skilled workers and their low levels of unemployment are important empirical facts. We plan to rework the pricing mechanism, as this will give us the opportunity to extend our analysis, as well as to further validate our results.

Whether and how our results will be influenced by a change of the pricing mechanism depends to a large degree on which type of firms is able to benefit more from this situation. An increase in the markup of capital goods firms would make inventions that save engineer labor more attractive, thus possibly mitigating a skill-bias against administrators. On the other hand, if consumption good firms increase their markup, this will have an impact on the demand for new capital goods (which would be decreased). This could then feed back on the employment of engineers, their wages and at a later stage on the direction of technological change. After all, we would also have to analyze how workers react to this inflationary tendencies. An alternative (or complementary) approach to mitigate this problem could be to assume that workers do not use up all of their funds for consumption but save some (like in Caiani et al. 2016).

13 Although, as we saw in Fig. 2, investment is still much more volatile than consumption and GDP. 


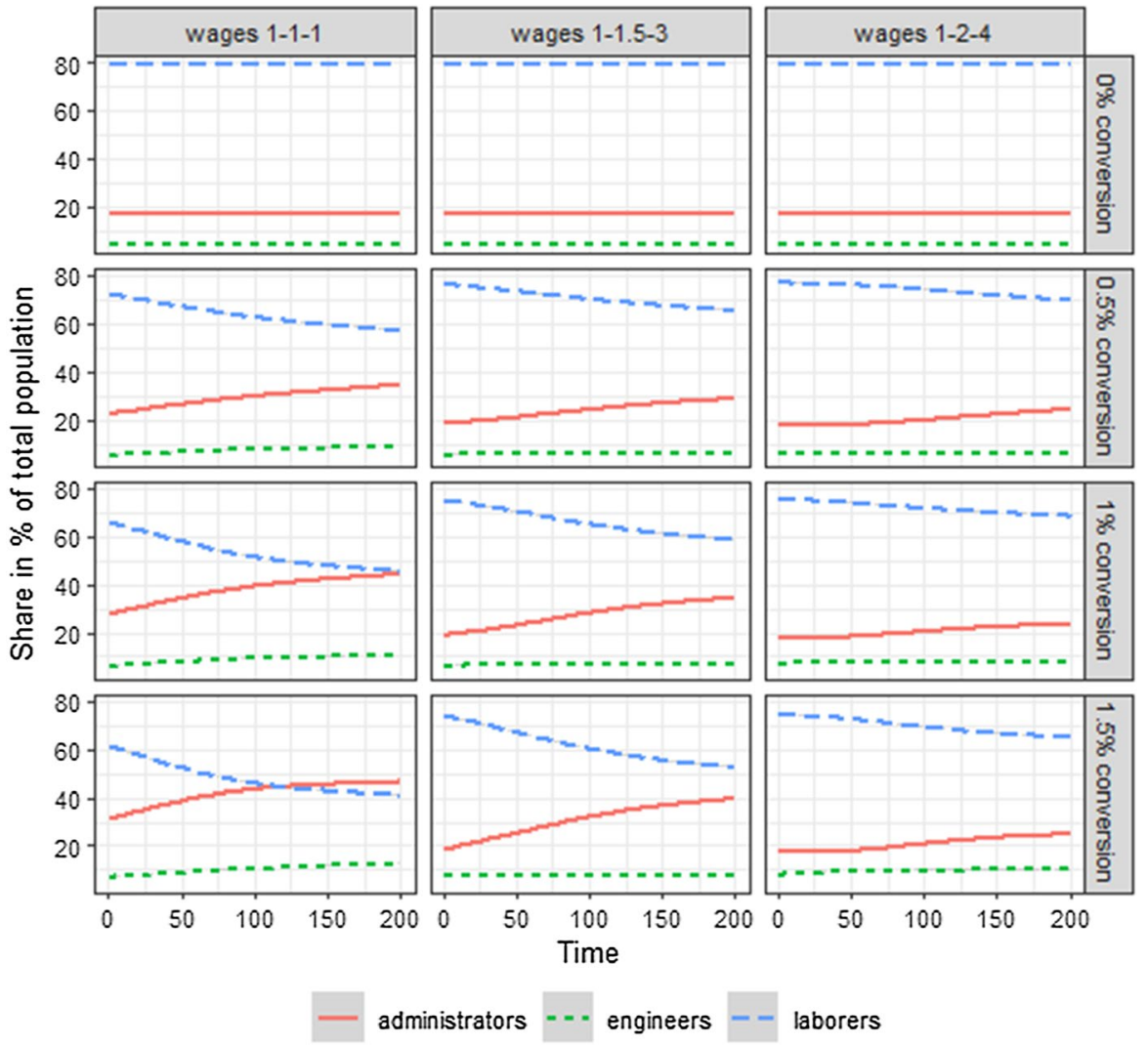

Fig. 16 Share of the different types of workers in $\%$ of the total population, with substitution and different initial wage settings

The government and the banking sector are obviously only crudely implemented to close the model and there are many ways to improve the model's depth in this area. Dosi et al. (2013) already implemented an interesting approach to the banking sector. At the moment, the bank's behavior is conditioned by its interest rate $\omega_{4}$ and the maximum sales to debt ratio $a^{\max }$. Higher $\omega_{4}$ and lower $a^{\max }$ would increase the frequency of insolvencies. Since firms are bailed out anyway, however, the results would be limited to reducing the heterogeneity of the supply side of the labor market, since insolvent firms adjust their wage offers to the average wages workers of a certain type receive. It would also be interesting to try to model a government that is acting in a more dynamic way (e.g. reacts to particular challenges). Currently, the behavior of the government is modeled with two parameters: the flat tax rate $\omega_{3}$ and 
the unemployment benefit rate $\omega_{1}$. A higher $\omega_{3}$ would decrease profits after taxes, which would again increase the likelihood of an insolvency in the long run with similar effects as described above for the bank. There are three main effects if $\omega_{1}$ gets larger: 1.) The reservation wage of workers increases, which means that they will bargain more often for a higher wage if they are employed and that they will be more reluctant to pick up a new job if they are unemployed. In the end, less vacancies will be filled and GDP declines starting at some level of $\omega_{1}$. 2.) Unemployed workers are able to consume more. Since unemployment is very unevenly distributed among the skill levels, administrators and laborers benefit on average from an increase in $\omega_{3}$. 3.) Nominal demand increases because of 2.). If there is excess supply, an increase in nominal demand increases GDP. Since-as discussed above-our economy almost always faces excess demand, however, GDP will not be affected from this increase. Instead, the results would be limited to the other consumers, who would not be able to buy as many consumption goods anymore, since they are then aliquoted according to the funds available. We can conclude that workers are unevenly affected from an increase in $\omega_{3}$. If the unemployment rate of a given type of worker is very low (as it is for engineers in any setting tested), workers of this type would be worse off. Administrators without substitution face on the other hand a very high unemployment rate, which means that they would on average benefit from an increase. For laborers, the effect is less clear and depends on the exact initial wage, upskilling and substitution settings, as well as on the level of $\omega_{3}$. A lower $\omega_{3}$ would have the exact opposite effects with the caveat that below a certain threshold a qualitative change would occur, since the "Keynesian" element of the model is bound to increase, i.e. GDP will be constrained due to excess supply, which would increase the rate of unemployment for all types of workers.

The consumption-savings decision of the model is also very simplified. In accord with Dosi et al. $(2010,2013)$ we assumed that workers fully consume their income. When we verified the model, however, it became apparent that workers are often not able to do so, since the market faces excess demand (as described above). We therefore assumed for simplicity that unused funds simply remain on the bank account of workers, who then try to use them in the next period. A more sophisticated consumption/savings decision of the households should involve either a savings target (like a retirement phase, housing, new products etc.) and/or be influenced by the interest rate (which then should be determined endogenously, which leads us to the aforementioned banking sector dynamics). As described before, such an extension could be an important step to resolve the issue of persisting excess demand. For these reasons, we do not propose to analyze industry evolution, inequality between capital and labor, the financial or government sector with our current model. We are also cautious about the implications of an increased "Keynesian" element on the magnitudes of the levels of income or unemployment. The "Keynesian" element could potentially also alleviate inequality, if it affects engineers more than laborers 
and it could make a case for the "Fordist" wage setting mechanism. It is, however, unlikely that it would change the direction or fundamental dynamics we are describing. We also corrected our findings for eventual excess demand by looking at real consumption and not only real wage data.

The fundamental dynamics of our model depend on the hierarchical structure of our model: the employment of engineers is only constrained by the demand for machines, while laborers employment is restricted by not only the demand for consumption goods, but also by the supply of machines (which need to be created by engineers first). The model is also an important exercise in the evaluation of longrun dynamics. In the long run and without technological change, our initial setting of 1-1-1 would lead to a full employment equilibrium with equal wages. But technological change needs time to diffuse: While engineers immediately start to produce newly developed machines, laborers will due to the long lifespan of machines always also use outdated equipment. Finally, our results crucially depend on the mechanism that firms employ to determine whether an invention/imitation leads to an innovation, as well as on the supply of the different types of workers and their initial productivities (which we, as already mentioned, calibrated to a long-run equilibrium). Engineers are a small minority and their skill premium can therefore (influenced by the other properties of our model mentioned) evolve to be very high, even if they start with none at all.

\section{Conclusion}

The driving forces of our model are wages, unemployment and technological change, which feed back to each other in multiple ways. Simply taking control of wages (either through initial setting or through the "Fordist" wage setting mechanism) is not enough to combat inequality, as firms will counter those policies by directing their innovation effort in a way that will re-establish vertical inequality (i.e. inequality between laborers and engineers) but also create horizontal inequality (i.e. between employed and unemployed laborers).

The main finding is that the market cannot simply be "tricked" into prices in the long term if powerful agents (in our case firms) are able to influence supply and demand and their power is left unchecked. In our case, firms react to high wages for laborers by limiting the demand for them via the channel of technological change (thus making their high wage acceptable at a certain point). In the real world, this might be complemented by other sources of power, e.g. firms may decide that domestic workers are too expensive and engage in offshoring activities. This behavior usually creates welfare losses-we saw that the GDP growth was lower when the technological development was directed towards "wrong" relative prices and not towards the real conditions at the labor market. 
The picture changes, however, if we move on from partial government intervention to a more holistic approach aimed at leveling the playing field. In our case, the introduction of upskilling enabled the workers to react to the changing requirements of labor market, thus countering the shift of demand with a shift of supply. In this state, the share of high skilled workers is much larger, but low skilled workers are pretty well off, too. At the same time, however, a minority (the initial population of engineers) would experience a smaller growth of their consumption and therefore may resist to those changes.

The reality is obviously a little bit more complex than our model. Training and education does not come for free and some people may not be able to learn new skills, even if resources are spent towards that goal. But since the dawn of capitalism, the education sector, as well as the overall skill level grew dramatically (albeit with some backlashes). On the one hand, this was necessary since many industries needed those skills. On the other hand, this was possible because we did not have to work on the fields all day anymore. The digital revolution provides a major challenge for today's societies. Where partial government intervention fails and creates perverse effects, holistic government intervention involving training and education may be able to distribute the skills necessary to meet this challenge and be successful in combating inequality at the same time. But that doesn't mean everybody would be happy about it.

Acknowledgements Open access funding provided by University of Graz. We are grateful to Andrea Roventini for answering our questions about the $\mathrm{K}+\mathrm{S}$ model and to Herbert Dawid, Christian Gehrke, Theresa Hager, Marlies Schütz, Laura Zillian, Stella Zillian and two anonymous reviewers, who commented on previous versions of this paper and thus helped to greatly improve the manuscript. We also thank the participants of the Graz Schumpeter Summer School 2018, the PhD colloquium of the Social Simulation Conference 2018 and the Doctoral School Economics of the University of Graz for their valuable feedback. All remaining errors are ours.

\section{Compliance with ethical standards}

Conflict of interest The authors declare that they have no conflict of interest.

Open Access This article is licensed under a Creative Commons Attribution 4.0 International License, which permits use, sharing, adaptation, distribution and reproduction in any medium or format, as long as you give appropriate credit to the original author(s) and the source, provide a link to the Creative Commons licence, and indicate if changes were made. The images or other third party material in this article are included in the article's Creative Commons licence, unless indicated otherwise in a credit line to the material. If material is not included in the article's Creative Commons licence and your intended use is not permitted by statutory regulation or exceeds the permitted use, you will need to obtain permission directly from the copyright holder. To view a copy of this licence, visit http://creativecommons.org/licen ses/by/4.0/.

\section{Appendix: Parameters and Variables}

Where possible, we calibrated the model according to the parameters specified in the original $\mathrm{K}+\mathrm{S}$ models. Due to restrictions in simulation capacity, however, our economy is populated by only half of their firms. 
Table 1 Parameters and their values

\begin{tabular}{|c|c|c|}
\hline \multicolumn{3}{|c|}{ Parameters } \\
\hline 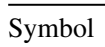 & Description & Initial value \\
\hline$i$ & Number of capital good firms & 25 \\
\hline$j$ & Number of consumption good firms & 100 \\
\hline$k$ & Number of machines & 800 per j firm \\
\hline$l$ & Number of laborers & 80000 \\
\hline$m$ & Number of administrators & 16832 \\
\hline$n$ & Number of engineers & 4160 \\
\hline$\phi^{\max }$ & Maximum life span of machines & 20 \\
\hline$\underline{z}_{J}$ & Minimum market share assigned to consumption good firms & 0.00001 \\
\hline $\bar{\mu}_{J}$ & Markup coefficient of consumption good firms & 0.04 \\
\hline$\varepsilon$ & Parameter for the expected growth of sales & 0.25 \\
\hline$\mu_{I}$ & Fixed markup of capital good firms & 0.05 \\
\hline$\tau_{J}$ & Payback period for investments & 3 \\
\hline$l_{1}$ & Proportion of newly addressed potential customers & 0.5 \\
\hline$l_{2}$ & Propensity to invest in $R \& D$ & 0.04 \\
\hline$l_{3}$ & Proportion of inventories desired by consumption good firms & 0.1 \\
\hline$v$ & Propensity to invest in invention & 0.5 \\
\hline$\zeta^{I N / I M}$ & Capability parameter for inventions and imitations & $0.3 / 0.3$ \\
\hline$\alpha, \beta$ & Parameters of beta distribution for inventions & 3,3 \\
\hline$\gamma, \bar{\gamma}$ & Supporters of beta distribution for inventions & $-0.15,0.15$ \\
\hline $\bar{\varsigma}$ & Production capacity of a machine & 40 \\
\hline$\psi_{1}$ & Wage setting parameter for aggregate productivity & 0.5 \\
\hline$\psi_{2}$ & Wage setting parameter for individual productivity & 0.5 \\
\hline$\psi_{3}, \psi_{4}$ & Competitiveness parameters & 1,1 \\
\hline$\omega_{1}$ & Unemployment benefit rate & 0.4 \\
\hline$\omega_{2}$ & Expected wage growth rate & 0.02 \\
\hline$\omega_{3}$ & Tax rate on profits & 0.1 \\
\hline$\omega_{4}$ & Interest rate on debt & 0.01 \\
\hline$a^{\max }$ & Maximum debt to sales ratio & 2 \\
\hline$\chi$ & Replicator dynamics & 1 \\
\hline
\end{tabular}

We calibrated the variables of our model in a way that firms do not expect any growth in the initial period. This fact is not extremely important, however, since we discard the first 50 periods as "burn-in periods" to let the model find its own growth path, just as the authors of the original Keynes + Schumpeter models do (see e.g. Dosi et al. 2010). Formulas are given instead of actual values for those variables, which depend on the initial wage settings. For instance, the price of a capital good depends on the wages of administrators and engineers. 


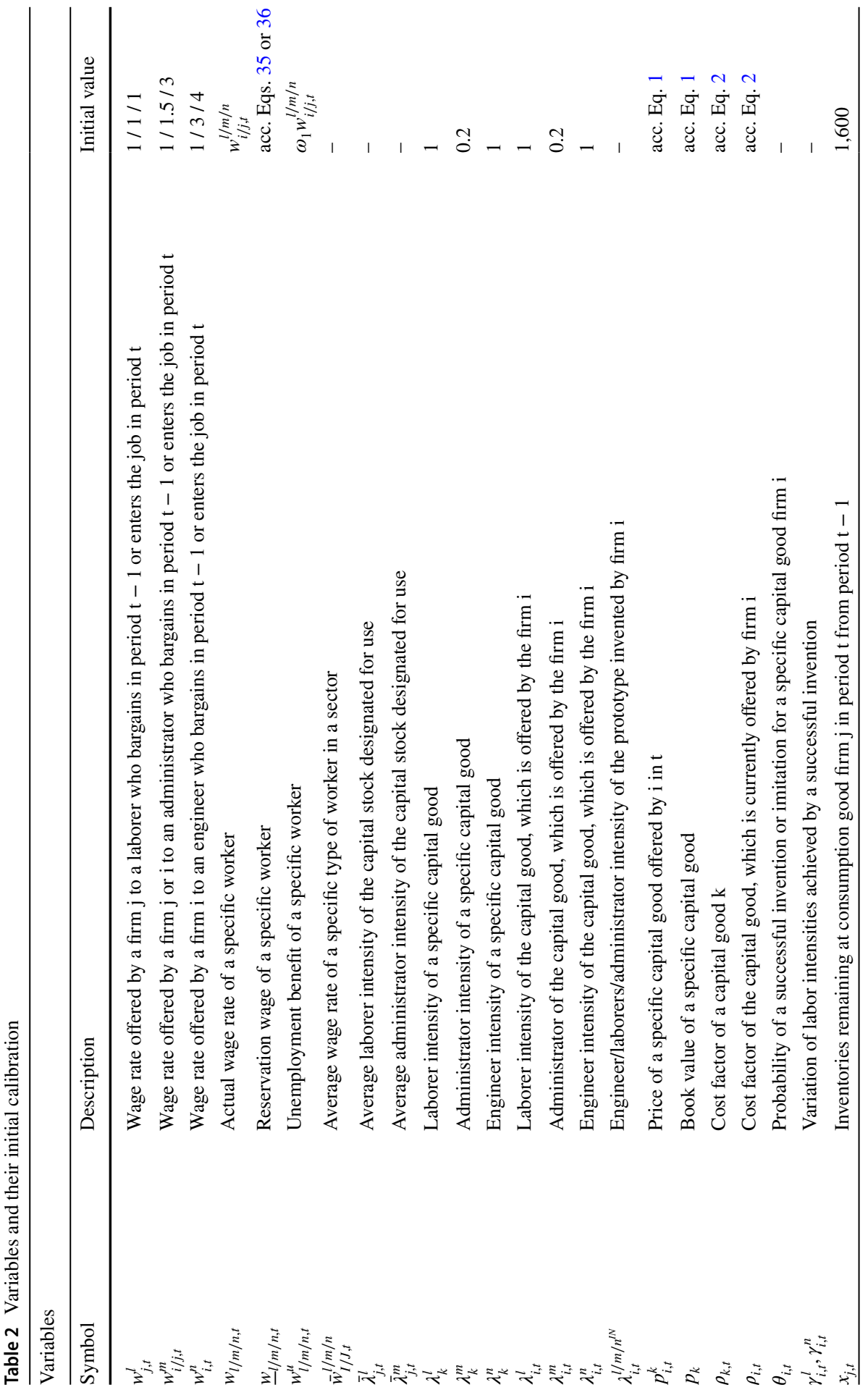




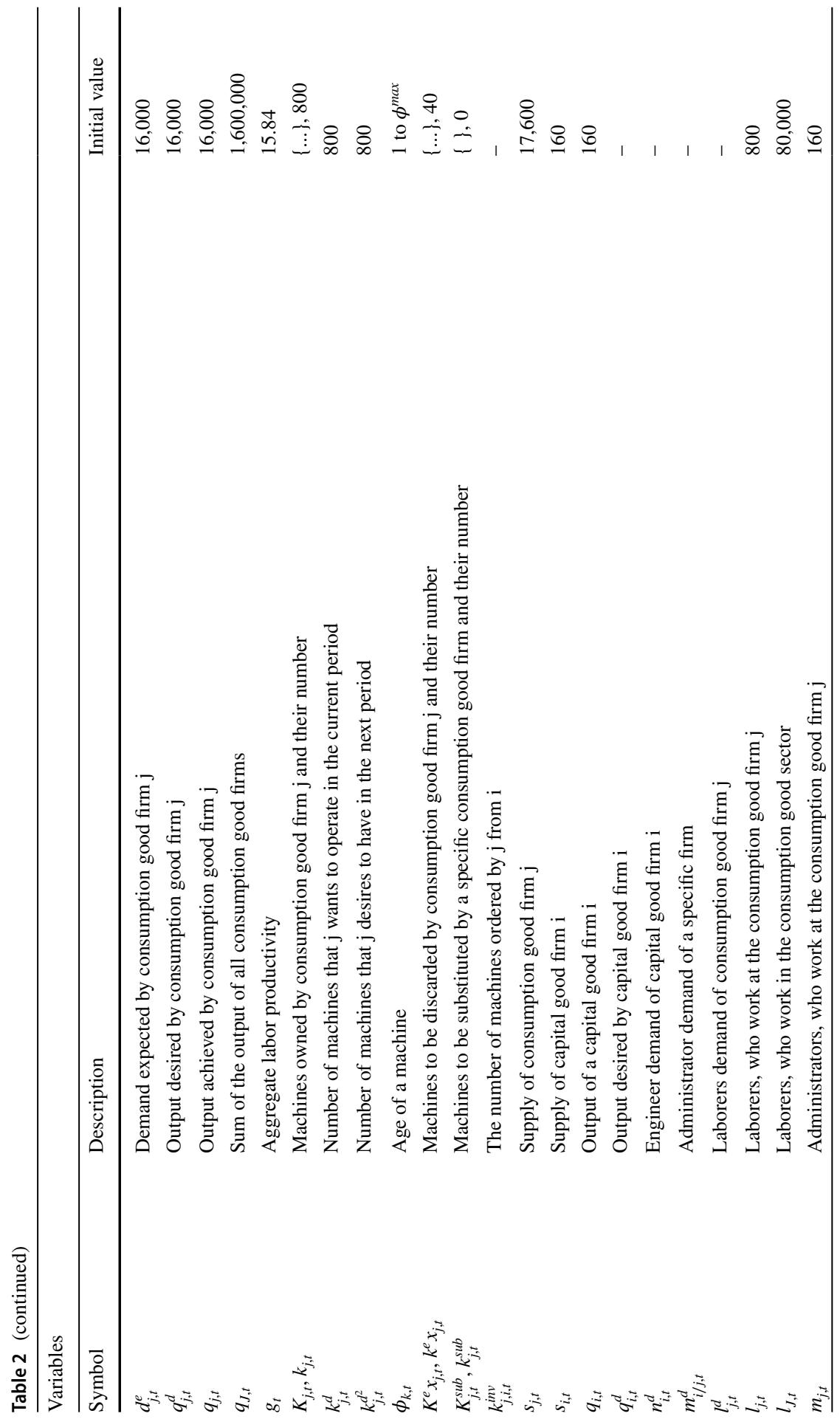




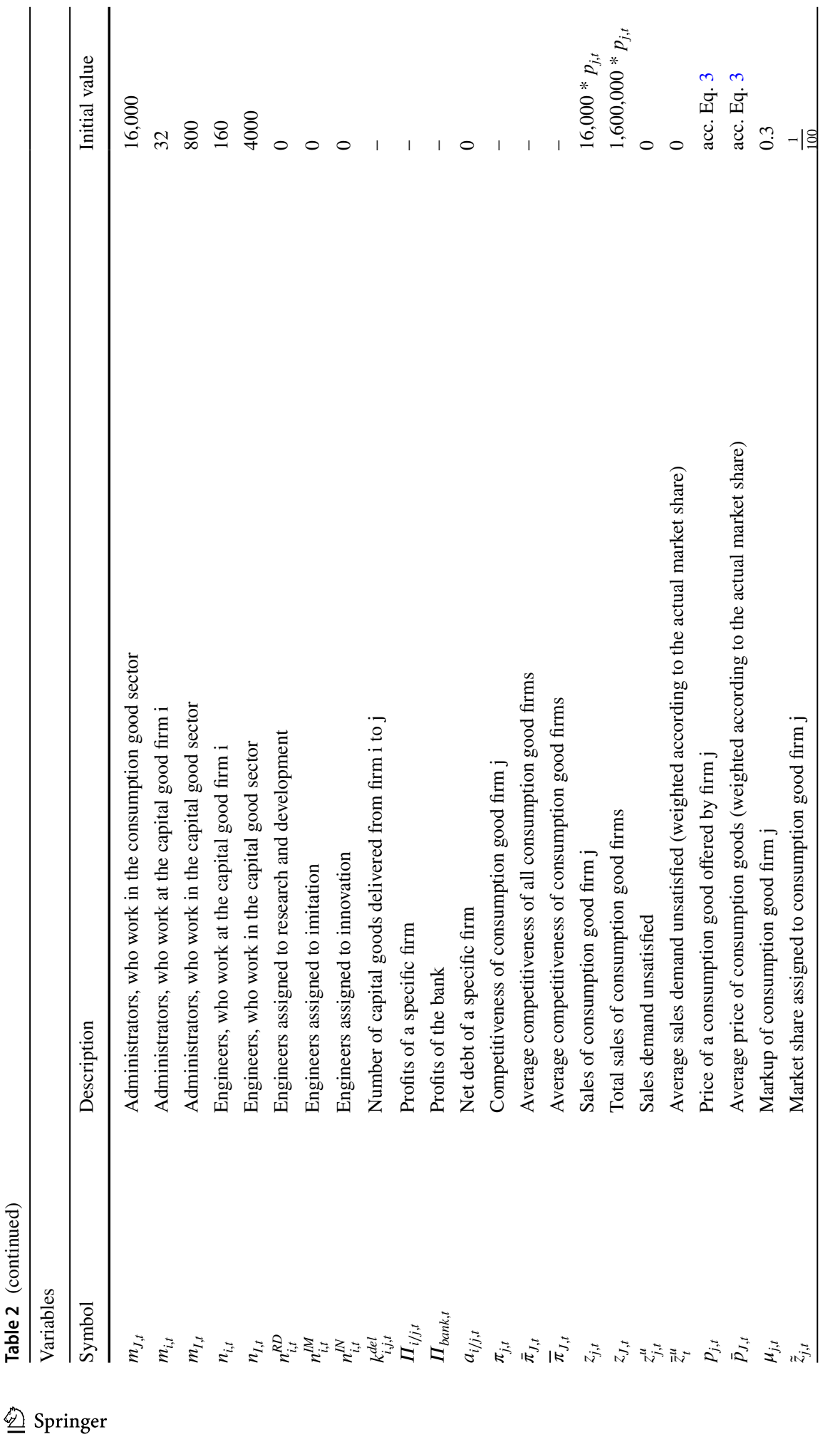




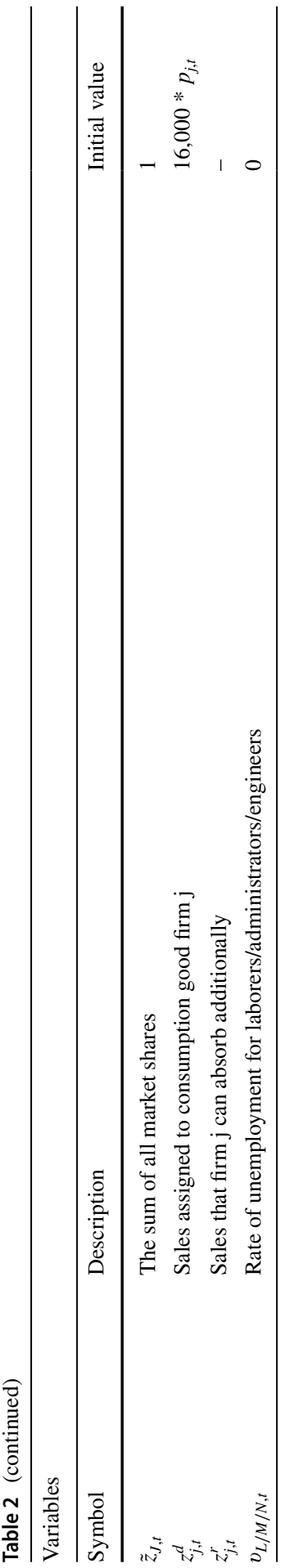




\section{References}

Acemoglu, D. (1998). Why do new technologies complement skills? Directed technical change and wage inequality*. The Quarterly Journal of Economics, 113(4), 1055-1089. https://doi. org/10.1162/003355398555838.

Acemoglu, D. (2002). Directed technical change. Review of Economic Studies, 69(4), 781-809. https:// doi.org/10.1111/1467-937x.00226.

Acemoglu, D., \& Restrepo, P. (2018a). Artificial intelligence, automation, and work. In The economics of artificial intelligence: An agenda, National Bureau of Economic Research, Inc (pp. 197-236). https ://EconPapers.repec.org/RePEc:nbr:nberch:14027.

Acemoglu, D., \& Restrepo, P. (2018b). Artificial intelligence, automation and work. Boston UniversityDepartment of Economics-Working Papers Series dp-298, Boston University-Department of Economics. https://doi.org/10.3386/w24196.

Acemoglu, D., \& Restrepo, P. (2018c). The race between man and machine: Implications of technology for growth, factor shares, and employment. American Economic Review, 108(6), 1488-1542. https:// doi.org/10.1257/aer.20160696.

Autor, D. H. (2014). Skills, education, and the rise of earnings inequality among the "other 99 percent". Science, 344(6186), 843-851. https://doi.org/10.1126/science.1251868.

Autor, D. H. (2015). Why are there still so many jobs? the history and future of workplace automation. Journal of Economic Perspectives, 29(3), 3-30. https://doi.org/10.1257/jep.29.3.3.

Autor, D. H., \& Dorn, D. (2013). The Growth of Low-Skill Service Jobs and the Polarization of the US Labor Market. American Economic Review, 103(5), 1553-1597. https://doi.org/10.1257/ aer.103.5.1553.

Autor, D. H., Katz, L. F., \& Krueger, A. B. (1998). Computing inequality: Have computers changed the labor market? The Quarterly Journal of Economics, 113(4), 1169-1213. https://doi. org/10.1162/003355398555874.

Autor, D. H., Levy, F., \& Murnane, R. J. (2003). The skill content of recent technological change: An empirical exploration. The Quarterly Journal of Economics, 118(4), 1279-1333. https://doi. org/10.1162/003355303322552801.

Brugger, F., \& Gehrke, C. (2017). The neoclassical approach to induced technical change: From hicks to acemoglu. Metroeconomica, 68(4), 730-776. https://doi.org/10.1111/meca.12141.

Brynjolfsson, E., \& McAfee, A. (2011). Race against the machine: How the revolution is accelerating innovation, driving productivity, and irreversibly transforming employment and the economy. Lexington, Mass: Digital Frontier Press.

Caiani, A., Godin, A., Caverzasi, E., Gallegati, M., Kinsella, S., \& Stiglitz, J. E. (2016). Agent basedstock flow consistent macroeconomics: Towards a benchmark model. Journal of Economic Dynamics and Control, 69, 375-408. https://doi.org/10.1016/j.jedc.2016.06.001.

Caiani, A., Russo, A., \& Gallegati, M. (2018). Are higher wages good for business? An assessment under alternative innovation and investment scenarios. Macroeconomic Dynamics, https://doi. org/10.1017/S1365100518000299.

Caiani, A., Russo, A., \& Gallegati, M. (2019). Does inequality hamper innovation and growth? An absfc analysis. Journal of Evolutionary Economics, 29(1), 177-228. https://doi.org/10.1007/s0019 1-018-0554-8.

Card, D. (2001). The effect of unions on wage inequality in the u.s. labor market. ILR Review, 54(2), 296-315. https://doi.org/10.1177/001979390105400206.

Chartrand, G., Cheng, P. M., Vorontsov, E., Drozdzal, M., Turcotte, S., Pal, C. J., et al. (2017). Deep learning: A primer for radiologists. RadioGraphics, 37(7), 2113-2131. https://doi.org/10.1148/ rg.2017170077. pMID: 29131760.

Darwin, C. (1859). On the origin of species by means of natural selection, or, the preservation of favoured races in the struggle for life. Journal of Murray London, https://doi.org/10.1017/cbo978051169429 5.

Dawid, H., \& Delli Gatti, D. (2018). Agent-based macroeconomics. In C. Hommes \& B. LeBaron (Eds.), Handbook of computational economics (Vol. 4, pp. 63-156)., Heterogeneous agent models Amsterdam: Elsevier.

Dawid, H., Gemkow, S., Harting, P., \& Neugart, M. (2009). On the effects of skill upgrading in the presence of spatial labor market frictions: An agent-based analysis of spatial policy design. Journal of Artificial Societies and Social Simulation, 12(4), 5. 
Dawid, H., Harting, P., \& Neugart, M. (2018). Cohesion policy and inequality dynamics: Insights from a heterogeneous agents macroeconomic model. Journal of Economic Behavior and Organization, 150, 220-255. https://doi.org/10.1016/j.jebo.2018.03.015.

Dosi, G., Fagiolo, G., \& Roventini, A. (2006). An evolutionary model of endogenous business cycles. Computational Economics, 27(1), 3-34. https://doi.org/10.1007/s10614-005-9014-2.

Dosi, G., Fagiolo, G., \& Roventini, A. (2008). The microfoundations of business cycles: An evolutionary, multi-agent model. Journal of Evolutionary Economics, 18(3), 413-432. https://doi.org/10.1007/ s00191-006-0050-4.

Dosi, G., Fagiolo, G., \& Roventini, A. (2010). Schumpeter meeting Keynes: A policy-friendly model of endogenous growth and business cycles. Journal of Economic Dynamics and Control, 34(9), 17481767. https://doi.org/10.1016/j.jedc.2010.06.018.

Dosi, G., Fagiolo, G., Napoletano, M., \& Roventini, A. (2013). Income distribution, credit and fiscal policies in an agent-based Keynesian model. Journal of Economic Dynamics and Control, 37(8), 1598-1625. https://doi.org/10.1016/S0165-1889(02)001.

Dosi, G., Fagiolo, G., Napoletano, M., Roventini, A., \& Treibich, T. (2015). Fiscal and monetary policies in complex evolving economies. Journal of Economic Dynamics and Control, 52(C), 166-189. https ://doi.org/10.1016/j.jedc.2014.11.01.

Dosi, G., Pereira, M., Roventini, A., \& Virgillito, M. (2019a). The labour-augmented k+s model: A laboratory for the analysis of institutional and policy regimes. EconomiA, https://doi.org/10.1016/j. econ.2019.03.002.

Dosi, G., Pereira, M. C., Roventini, A., \& Virgillito, M. (2017). When more flexibility yields more fragility: The microfoundations of Keynesian aggregate unemployment. Journal of Economic Dynamics and Control, 81(C), 162-186. https://doi.org/10.1016/j.jedc.2017.05.00.

Dosi, G., Roventini, A., \& Russo, E. (2019). Endogenous growth and global divergence in a multi-country agent-based model. Journal of Economic Dynamics and Control, 101, 101-129. https://doi. org/10.1016/j.jedc.2019.02.005.

Dow, J. C. R., \& Dicks-Mireaux, L. A. (1958). The excess demand for labour: A study of conditions in great britain, 1946-56. Oxford Economic Papers, 10(1), 1-33.

Frey, C. B., \& Osborne, M. A. (2017). The future of employment: How susceptible are jobs to computerisation? Technological Forecasting and Social Change, 114(C), 254-280. https://doi.org/10.1016/j. techfore.2016.08.019.

Georges, C. (2017). Innovation and consumption inequality in an agent-based macroeconomic model. Tech. rep., Hamilton College. https://doi.org/10.2139/ssrn.2923786.

Goldin, C., \& Katz, L. F. (2007). Long-run changes in the wage structure: Narrowing, widening, polarizing. Brookings Papers on Economic Activity, 38(2), 135-168. https://doi.org/10.1353/ eca.2008.0000.

Goos, M., \& Manning, A. (2007). Lousy and lovely jobs: The rising polarization of work in britain. The Review of Economics and Statistics, 89(1), 118-133.

Goos, M., Manning, A., \& Salomons, A. (2009). Job polarization in Europe. The American Economic Review, 99(2), 58-63. https://doi.org/10.1257/aer.99.2.58.

Helpman, E. (2017). Globalization and wage inequality. Journal of the British Academy, 5, 125-162.

Kaldor, N. (1957). A model of economic growth. The Economic Journal, 67(268), 591-624. https://doi. org/10.2307/2227704.

Nelson, R. R., \& Winter, S. G. (1982). An evolutionary theory of economic change. Cambridge, Mass: Belknap Press of Harvard University Press. https://doi.org/10.2307/1058233.

Neves, F., Campos, P., \& Silva, S. (2019). Innovation and employment: An agent-based approach. Journal of Artificial Societies and Social Simulation, 22(1), 8. https://doi.org/10.18564/jasss.3933.

Palagi, E., Napoletano, M., Roventini, A., \& Gaffard, J. L. (2017). Inequality, redistributive policies and multiplier dynamics in an agent-based model with credit rationing. Italian Economic Journal, 3, 367-387.

Phillips, A. W. (1958). The relation between unemployment and the rate of change of money wage rates in the united kingdom, 1861-19571. Economica, 25(100), 283-299. https://doi. org/10.1111/j.1468-0335.1958.tb00003.x.

Ponta, L., Raberto, M., Teglio, A., \& Cincotti, S. (2018). An agent-based stock-flow consistent model of the sustainable transition in the energy sector. Ecological Economics, 145(C), 274-300.

Pontusson, J. (2013). Unionization, inequality and redistribution. British Journal of Industrial Relations, 51(4), 797-825. https://doi.org/10.1111/bjir.12045. 
R Core Team (2013) R: A language and environment for statistical computing. R Foundation for Statistical Computing, Vienna, Austria. http://www.R-project.org/.

Sarkar, D. (2008). Lattice: Multivariate data visualization with R. Springer, New York. http://lmdvr .r-forge.r-project.org, iSBN 978-0-387-75968-5.

Schumpeter, J. A., \& ([1934], 2012). The theory of economic development : An inquiry into profits, capital, credit, interest, and the business cycle. New Brunswick and London: Transaction Publishers.

Silva, S. T., Valente, J. M. S., \& Teixeira, A. A. C. (2012). An evolutionary model of industry dynamics and firms' institutional behavior with job search, bargaining and matching. Journal of Economic Interaction and Coordination, 7(1), 23-61. https://doi.org/10.1007/s11403-011-0085-y.

Song, J., Price, D. J., Guvenen, F., Bloom, N., \& von Wachter, T. (2018). Firming up inequality*. The Quarterly Journal of Economics, 134(1), 1-50. https://doi.org/10.1093/qje/qjy025.

Vallejos, H. A., Nutaro, J. J., \& Perumalla, K. S. (2018). An agent-based model of the observed distribution of wealth in the united states. Journal of Economic Interaction and Coordination, 13(3), 641-656. https://doi.org/10.1007/s11403-017-0200-9.

Wickham, H. (2009). ggplot2: Elegant graphics for data analysis. New York: Springer.

Wilensky, U. (1999). Netlogo. http://ccl.northwestern.edu/netlogo/, Center for Connected Learning and Computer-Based Modeling, Northwestern University, Evanston, IL, http://ccl.northwestern.edu/ netlogo/.

Publisher's Note Springer Nature remains neutral with regard to jurisdictional claims in published maps and institutional affiliations. 